\title{
Crystal structure of the 6-phosphogluconate dehydrogenase
}

\section{from Gluconobacter oxydans reveals tetrameric 6PGDHs as the}

\section{crucial intermediate in the evolution of structure and}

\section{cofactor preference in the 6PGDH family [version 1; peer}

\section{review: 1 approved, 1 approved with reservations]}

\author{
Pablo Maturana (iD), Eduardo Tobar-Calfucoy(D)1, Matías Fuentealba(iD)1,2, \\ Pietro Roversi (D), Richard Garratt ${ }^{4}$, Ricardo Cabrera1 \\ ${ }^{1}$ Laboratorio de Bioquímica y Biología Molecular, Departamento de Biología, Universidad de Chile, Santiago, Chile \\ 2Institute of Healthy Aging, Department of Genetics, Evolution and Environment, University College London, London, England, UK \\ ${ }^{3}$ Leicester Institute of Chemical and Structural Biology and Department of Molecular and Cell Biology, University of Leicester, \\ Leicester, Henry Wellcome Building, England, UK \\ ${ }^{4}$ Instituto de Fisica de São Carlos, Universidade de São Paulo, São Carlos, São Paulo, Brazil
}

V1 First published: 04 Mar 2021, 6:48

https://doi.org/10.12688/wellcomeopenres.16572.1

Latest published: 04 Mar 2021, 6:48

https://doi.org/10.12688/wellcomeopenres.16572.1

\section{Abstract}

Background: The enzyme 6-phosphogluconate dehydrogenase (6PGDH) is the central enzyme of the oxidative pentose phosphate pathway. Members of the 6PGDH family belong to different classes: either homodimeric enzymes assembled from long-chain subunits or homotetrameric ones assembled from short-chain subunits. Dimeric 6PGDHs bear an internal duplication absent in tetrameric 6PGDHs and distant homologues of the $\beta$-hydroxyacid dehydrogenase ( $\beta H A D H)$ superfamily.

Methods: We use X-ray crystallography to determine the structure of the apo form of the 6PGDH from Gluconobacter oxydans (Go6PGDH). We carried out a structural and phylogenetic analysis of short and long-chain 6PGDHs. We put forward an evolutionary hypothesis explaining the differences seen in oligomeric state vs. dinucleotide preference of the 6PGDH family. We determined the cofactor preference of Go6PGDH at different 6-phosphogluconate concentrations, characterizing the wild-type enzyme and three-point mutants of residues in the cofactor binding site of Go6PGDH.

Results: The structural comparison suggests that the $6 \mathrm{PG}$ binding site initially evolved by exchanging C-terminal a-helices between subunits. An internal duplication event changed the quaternary structure of the enzyme from a tetrameric to a dimeric arrangement. The phylogenetic analysis suggests that 6PGDHs have spread from Bacteria to Archaea

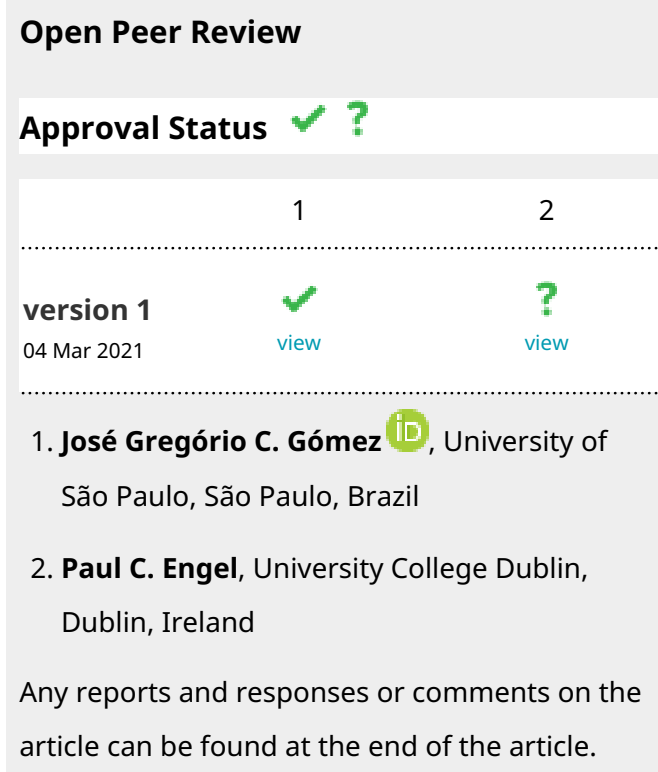


and Eukarya on multiple occasions by lateral gene transfer. Sequence motifs consistent with $\mathrm{NAD}^{+}$- and NADP ${ }^{+}$-specificity are found in the 32-a2 loop of dimeric and tetrameric 6PGDHs. Site-directed mutagenesis of G06PGDH inspired by this analysis fully reverses dinucleotide preference. One of the mutants we engineered has the highest efficiency and specificity for $\mathrm{NAD}^{+}$so far described for a 6PGDH.

Conclusions: The family 6PGDH comprises dimeric and tetrameric members whose active sites are conformed by a C-terminal a-helix contributed from adjacent subunits. Dimeric 6PGDHs have evolved from the duplication-fusion of the tetrameric C-terminal domain before independent transitions of cofactor specificity. Changes in the conserved $\beta 2$ - $\alpha 2$ loop are crucial to modulate the cofactor specificity in Go6PGDH.

\section{Keywords}

6PGDH, 6-phosphogluconate dehydrogenase, enzyme superfamily evolution, cofactor specificity engineering, oxidative pentose phosphate pathway, X-ray crystallography

Corresponding authors: Pablo Maturana (pmaturana.v@gmail.com), Ricardo Cabrera (ricabrer@uchile.cl)

Author roles: Maturana P: Conceptualization, Formal Analysis, Funding Acquisition, Investigation, Methodology, Supervision, Validation, Visualization, Writing - Original Draft Preparation, Writing - Review \& Editing; Tobar-Calfucoy E: Formal Analysis, Investigation, Methodology; Fuentealba M: Formal Analysis, Investigation, Methodology; Roversi P: Data Curation, Formal Analysis, Funding Acquisition, Investigation, Methodology, Writing - Review \& Editing; Garratt R: Formal Analysis, Funding Acquisition, Validation, Visualization, Writing - Review \& Editing; Cabrera R: Conceptualization, Formal Analysis, Funding Acquisition, Project Administration, Resources, Supervision, Validation, Writing - Original Draft Preparation, Writing - Review \& Editing

Competing interests: No competing interests were disclosed.

Grant information: This work was supported by the Wellcome Trust through a Seed Award in Science [214090, https://doi.org/10.35802/214090] and Institutional Strategic Support Fund grant [204801, https://doi.org/10.35802/204801] to PR. This work was also supported by FONDECYT [1121170], FONDEQUIP [EQM140151], VID [ENL012/16] (University of Chile), PAIFAC (Faculty of Sciences, University of Chile). RC was partially supported by CINV, a Millennium Institute from the Scientific Initiative of the Ministerio de Economía, Fomento y Turismo. PM was supported by CONICYT Chilean fellowships.

The funders had no role in study design, data collection and analysis, decision to publish, or preparation of the manuscript.

Copyright: @ 2021 Maturana P et al. This is an open access article distributed under the terms of the Creative Commons Attribution License, which permits unrestricted use, distribution, and reproduction in any medium, provided the original work is properly cited.

How to cite this article: Maturana P, Tobar-Calfucoy E, Fuentealba M et al. Crystal structure of the 6-phosphogluconate dehydrogenase from Gluconobacter oxydans reveals tetrameric 6PGDHs as the crucial intermediate in the evolution of structure and cofactor preference in the 6PGDH family [version 1; peer review: 1 approved, 1 approved with reservations] Wellcome Open Research 2021, 6:48 https://doi.org/10.12688/wellcomeopenres.16572.1

First published: 04 Mar 2021, 6:48 https://doi.org/10.12688/wellcomeopenres.16572.1 


\section{Introduction}

6-phosphogluconate dehydrogenases (6PGDHs) (EC 1.1.1.44) catalyse the oxidative decarboxylation of the $\beta$-hydroxyacid 6-phosphogluconate (6PG) to yield ribulose 5-phosphate ${ }^{1}$. 6 PGDHs have been characterized from bacterial, archaeal and eukaryal species. They are either homodimeric enzymes made of long-chain subunits (about $52 \mathrm{kDa}$ ) or homotetrameric enzymes made of short-chain subunits (about $35 \mathrm{kDa}$ ) - although a recent report proposed a dimeric oligomeric state for a short-chain $6 \mathrm{PGDH}^{2}$. Pickl and Schonheit were the first to reveal that long- and short-chain 6PGDHs form separated clusters (subfamilies) in a phylogenetic tree ${ }^{3}$. In spite of the current available structural knowledge of short- and long-chain 6PGDHs and other homologous $\beta$-hydroxyacid dehydrogenases, the structural changes associated with the evolution of the 6PG-binding site have not been taken into consideration in order to understand the constraints substrate binding imposed on 6PGDH sequence length and oligomeric state. Moreover, evolution of cofactor specificity in 6PGDHs remains relatively understudied. To address these questions, we provide here a structural evolutionary framework that considers 6PGDH structures jointly with their phylogeny - both at the family and superfamily levels- and looks at the phylogenetic distribution of the 6PGDH residues mediating cofactor binding.

Short-chain 6PGDHs are reminiscent of their most distant relatives in the $\beta$-hydroxyacid dehydrogenases ( $\beta$-HADHs) superfamily ${ }^{4}$, tetrameric enzymes that carry out the oxidation of a hydroxyl group in the $\beta$-position to an acidic moiety in substrates such as 3-hydroxy-isobutyrate (3HIBA) and glycerate $^{5}$, serine ${ }^{6}$, 3-hydroxy-propionate ${ }^{7}$, tartronate $^{8}$ and 2-hydroxy-propyl-phosphonate ${ }^{9}$. However, compared to $\beta$-HADHs, which generally show some substrate promiscuity ${ }^{5,7}$, reports on 6PGDHs do not support oxidation of $\beta$-hydroxyacids other than $6 \mathrm{PG}$.

$\beta$-HADHs generally assemble as a dimer of dimers. The tertiary structure of the archetypical $\beta$-HADH subunit is composed of two domains: an N-terminal Rossmann fold domain (with additional structural elements) that harbours the dinucleotide cofactor binding site (either $\mathrm{NAD}^{+}$or $\mathrm{NADP}^{+}$); and a $\mathrm{C}$-terminal helical domain that harbours the $\beta$-hydroxyacid $\left(\beta\right.$-HA) substrate site and provides oligomerization interfaces ${ }^{10}$. In the case of dimeric, long-chain 6PGDHs enzymes, the $\mathrm{N}$-terminal domain is followed by a tandem array of two helical domains $^{11}$ (named hemi-domains hereafter), mediating the formation of the dimer. In these 6PGDH dimers the interface between two hemi-domains within a monomer is equivalent to the interface between two $\beta$-HADH monomers in a $\beta$-HADH dimer. Likewise, the interface that holds two monomers together in a long-chain 6PGDH dimer is akin to that between dimers in the $\beta$-HADH dimer of dimers (Figure $1 \mathrm{~A}$ and $\mathrm{B})^{10,12,13}$. These observations originated the hypothesis that the structure of one long-chain 6PGDH subunit probably evolved from a $\beta$-HADH precursor by gene duplication and fusion, followed by deletion of the $\mathrm{N}$-terminal domain ${ }^{10}$.

We posit that inclusion of short-chain 6PGDHs in the phylogeny of this hypothetical evolutionary pathway can reveal a connection between the structural changes underpinning 6PG binding and the duplication of the helical domain concurrent to the change in 6PGDH oligomerization state.
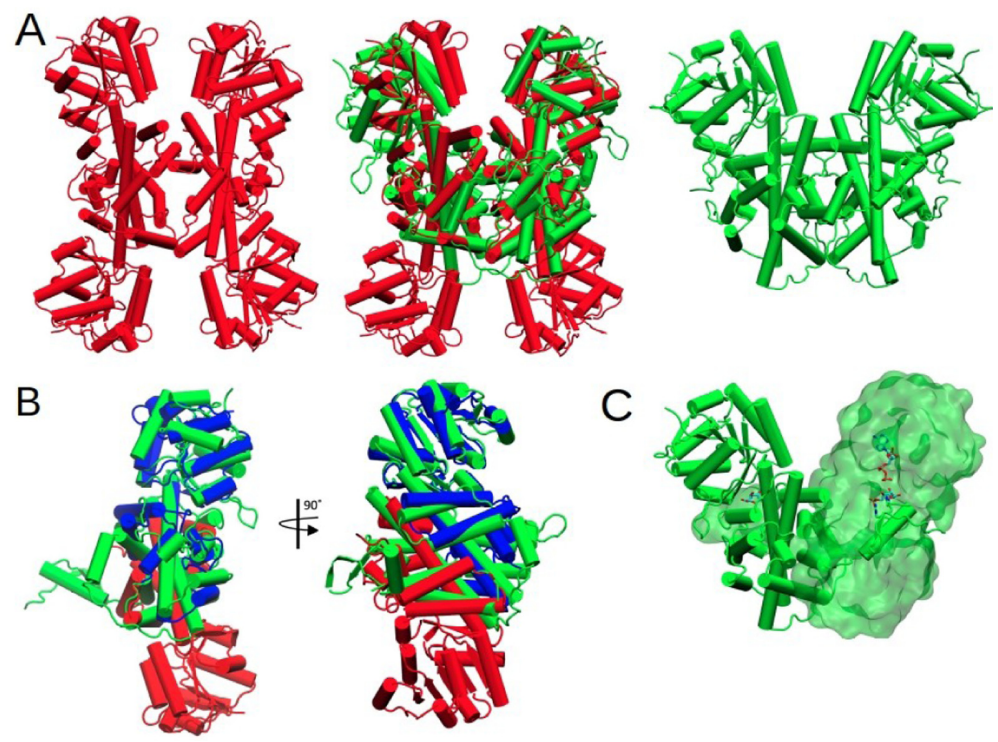

Figure 1. Structural correlations among the $\boldsymbol{\beta}$ HADH superfamily. (A) Structural superposition (center) of quaternary structure of the tetrameric human 3HIBADH (PDBid: 2I9P, left) and the dimeric EC6PGDH (PDBid: 3FWN, right). (B) Structural correlation between the monomeric form of EC6PGDH and the obligate dimer of the human 3HIBADH. The N-terminal domain and repeated C-terminal hemi-domains of a monomer EC6PGDH (green) align with two packeted hemi-domains from the obligate dimer of the tetramer 3HIBADH (subunits in red and blue). (C) Structure of the dimeric EC6PGDH, one subunit is represented in cartoon and another subunit in surface. Both subunits contribute the active site through the exchange of the last C-terminal alpha helix. 
The structural determinants of specificity for substrate and dinucleotides in 6PGDHs have been studied mainly using long-chain enzymes. When it comes to the 6PG binding site, a crystal structure of the sheep and E. coli dimeric 6PGDH in complex with 6PG shows that the phosphate moiety and the nearby hydroxyl groups of 6PG in one subunit are contacted by residues on the C-terminal $\alpha$-helix, belonging to the other subunit in the dimer (Figure 1C) ${ }^{11,14}$. Hawes et al. in 1996 pointed out that the presence of this $\alpha$-helix distinguishes 6PGDHs from 3HIBA dehydrogenases ${ }^{15}$. Recent crystal structures of longchain dimeric 6PGDHs complexes with $6 \mathrm{PG}^{16-18}$ confirm strong structural conservation of the enzyme: 6PG interactions in the binding site across the superfamily.

With regard to the dinucleotide cofactor binding site, sequence motifs consistent with $\mathrm{NAD}^{+}$- and $\mathrm{NADP}^{+}$-specificity are found in the N-terminal domain $\beta 2-\alpha 2$ loop of both dimeric and tetrameric 6PGDHs. Crystal structures of long-chain 6PGDHs uncovered in the $\beta 2-\alpha 2$ loop an $\mathrm{NRX}_{3} \mathrm{~K}$ motif which provides favorable interactions with $\mathrm{NADP}^{+}$, thereby explaining the preference for this particular dinucleotide $\operatorname{cofactor}^{17,19,20}$. In particular, the Asn and Arg residues at the beginning of the $\mathrm{NRX}_{3} \mathrm{~K}$ motif bind the 2'-phosphate group of the dinucleotide with H-bonds and a salt bridge, and the guanidinium moiety of the same arginine residue also interacts with the adenine ring of the cofactor through $\pi$-stacking. Residues in the $\mathrm{NRX}_{3} \mathrm{~K}$ motif determine the cofactor preference of $6 \mathrm{PGDHs}^{21}$. For example, the $\mathrm{NR}$ motif found in $\mathrm{NADP}^{+}$-dependent 6PGDHs changes to $\mathrm{D}[\mathrm{I} / \mathrm{L} / \mathrm{R}]$ in the sequences of $6 \mathrm{PGDH}$ s that can use $\mathrm{NAD}^{+}$ as the cofactor $^{22}$. In particular, the sequences of 6PGDHs from acetic acid bacteria show the DR motif, which correlates with the utilization of both cofactors ${ }^{2}$. Among them, the 6PGDH from Gluconobacter oxidans (Go6PGDH) compared to that of Gluconoacetobacter diazotrophicus (Gd6PGDH) possesses higher specificity constants for both cofactors and thus it might serve as a useful model to study the residues that determine the dinucleotide specificity of short-chain 6PGDHs.

Phylogenetic studies of 6PGDHs have revealed Lateral Gene Transfer (LGT) events and suggested a correlation between cofactor preference and subunit size. So far, dimeric 6PGDHs have been characterized from eukaryotes and eubacteria only. Krepinsky et al. ${ }^{23}$ showed that animal and fungal cytosolic 6PGDH sequences cluster with their orthologues from $\gamma$-proteobacteria. However, these authors speculated that once $\alpha$-proteobacteria sequences become available, their 6PGDH sequences would be expected (as mitochondrial ancestors) to be even closer to eukaryotic ones than those of $\gamma$-proteobacteria. On the other hand, tetrameric 6PGDHs have been found only in prokaryotes ${ }^{24-26}$. Pickl and Schönheit ${ }^{3}$ found a phylogenetic cluster of haloarchaeal 6PGDH sequences flanked by bacterial sequences and concluded they were likely the result of an LGT event. They also noted that, while the kinetically characterized tetrameric 6PGDHs were $\mathrm{NAD}^{+}$-dependent, the dimeric ones were $\mathrm{NADP}^{+}$-dependent. A more recent study also recognized that sequence patterns in the nucleotide binding site of short-chain 6PGDHs suggest that they would be $\mathrm{NAD}^{+}$-dependent ${ }^{2}$. However, a tetrameric 6PGDH from a thermophilic bacterium has been reported whose catalytic efficiency with $\mathrm{NADP}^{+}$was far higher than with $\mathrm{NAD}^{+27}$. Therefore, at the family level, it is important to clarify the main phylogenetic relationships and the evolution of cofactor specificity of 6PGDHs.

In this work, we describe the crystallographic structure of the tetrameric Go6PGDH and use it to study the structural evolution of the $\beta$-HADHs fold. We find that the active site remodeling required to establish the $6 \mathrm{PG}$ binding site implies that short-chain 6PGDHs must conserve a tetrameric structure for full activity. Our rooted phylogenetic tree of the 6PGDH family indicates that while long-chain 6PGDHs have been transferred from Bacteria to Eukarya, short-chain 6PGDHs were transferred from Bacteria to Archaea, and provide evidence that $\mathrm{NAD}^{+}$and $\mathrm{NADP}^{+}$-dependent groups could be found in both short and long-chain subfamilies. Finally, enzyme kinetics of Go6PGDH and site-directed mutagenesis of the conserved DR motif allowed us to obtain a mutant with the highest activity and selectivity towards $\mathrm{NAD}^{+}$so far described for 6PGDHs.

\section{Methods}

\section{Molecular cloning and site-directed mutagenesis}

The gene gox1705 from Gluconobacter oxidans present in the plasmid pASK-IBA3plus (plasmid pASK-IBA3plus-gox1705 was granted by Uwe Deppenmeier from the Institute für Mikrobiologie und Biotechnologie, Bonn University, Germany in $2012^{28}$ ), was subcloned into the pET-TEV-28a plasmid. The pET-TEV plasmid was derived from pET28-a (Millipore Sigma \#69864-3) by insertion of the TEV cleavage site and removing the thrombin cleavage site and $\mathrm{T} 7 \mathrm{tag}$. This manipulation was important to avoid the presence of a streptavidin tag fusion in the C-terminal region of the expressed protein int the pASK-IBA3plus plasmid, because of its role in 6PG binding. The pET-TEV plasmid was a kind donation of Dr. Adriana Krapp to R. Cabrera (research stay 2010 at the Laboratory of Dr. Néstor Carrillo, Instituto de Biología Molecular y Celular de Rosario, Argentina). Primers were designed to introduce a site for NdeI in frame with the start codon of gox1705 (Forward primer: CATATGCGGATCGGAAT-CATCGGACTG), and a site for XhoI downstream of its stop codon (Reverse primer: CTCGAGTAATTTTCTTTTC-GACGTGTCCGCCG). The PCR product and pET-TEV plasmid were digested with one enzymatic unit (U) of NdeI (ThermoScientific \#FD0583) and XhoI (ThermoScientific \# FD0694) in FastDigest ${ }^{\circledR}$ buffer (ThermoFisher) at $37{ }^{\circ} \mathrm{C}$ for one hour and ligated with $5 \mathrm{U}$ of T4 DNA Ligase (ThermoScientific \#EL0011) at $20^{\circ} \mathrm{C}$ over night. Colonies were evaluated for protein expression. The resulting plasmid (named pET-TEV-Go6PGDH) expressed the full Go6PGDH coding sequence preceded by 21 amino acids, including a 6xHis tag at the $\mathrm{N}$-terminal end and a cleavage site for the TEV protease before the first Met of Go6PGDH. After treatment with TEV protease, a dipeptide (Gly-His) remains at the N-terminus of Go6PGDH immediately preceding its first Met. Site-directed mutagenesis was performed by PCR amplification of pET-TEV-Go6PGDH, using mutagenic primers, according to the Genetailor ${ }^{\mathrm{TM}}$ site-directed mutagenesis system (Invitrogen \#A13282). To ensure that no spurious mutations had been introduced, the entire ORF was subsequently sequenced (Macrogen USA). 


\section{Expression and protein purification}

Go6PGDH and Ec6PGDH were expressed in E. coli strain BL21(DE3) as described by Olavarria et al. ${ }^{29}$. Briefly, cells of E.coli strain BL21(DE3) carrying the pET-TEV-28a-Go6PGDH wild-type, site-directed mutants or pET-TEV-28a-Ec6PGDH plasmids were inoculated in Luria-Bertani culture medium at $37{ }^{\circ} \mathrm{C}$. When the attenuance reached $0.4-0.5 \mathrm{AU}$ at $600 \mathrm{~nm}$, over-expression was induced by adding $1 \mathrm{~mm}$ isopropyl- $\beta$-Dthiogalactoside (US Biological Swampscott, MA, USA). After $4 \mathrm{~h}$ of induction at $37{ }^{\circ} \mathrm{C}$ in the case of Ec6PGDH expression and $16 \mathrm{~h}$ at $28^{\circ} \mathrm{C}$ in the case of Go6PGDH wild-type and mutants, biomass were collected by centrifugation (10 $\mathrm{min}, 4500 \mathrm{~g}$, $4{ }^{\circ} \mathrm{C}$ in a Thermo Scientific ${ }^{\mathrm{TM}}$ Sorvall ${ }^{\mathrm{TM}} \mathrm{RC} 6$ Plus Centrifuge), and in each case, the cell extract was loaded onto a $5 \mathrm{ml}$ HisTrap HP column (GE Healthcare, Lit tle Chalfont, UK), equilibrated with the resuspension buffer: $50 \mathrm{mM}$ Tris- $\mathrm{HCl}, 500 \mathrm{mM} \mathrm{NaCl}$, $40 \mathrm{mM}$ Imidazole, $\mathrm{pH}$ 8.0. For elution, a continuous flow of the resuspension buffer with a linear gradient of imidazole from $40 \mathrm{mM}$ to $500 \mathrm{mM}$ was used. The enzyme activity was measured using $0.4 \mathrm{mM} \mathrm{NAD}^{+}$(Sigma-Aldrich \# N1511) and $2 \mathrm{mM}$ 6PG (Sigma-Aldrich \# P7877) in the same resuspension buffer (without imidazole), and the Bradford assay was used to monitor the protein concentration. The fractions with activity were pooled. Overnight TEV protease digestion removed the 6xHis tail at room temperature in buffer Tris- $\mathrm{HCl} 50 \mathrm{mM}, 1 \mathrm{mM}$ TCEP (Sigma-Aldrich \# 646547), 0.5 mM EDTA, pH 8.0 using a molar ratio protease:enzyme of 1:10. After protein digestion, the mixture was centrifuged to remove the aggregate and reloaded onto a HisTrap column to remove the TEV protease (which also contained a His tail). The eluted enzyme was dialyzed and concentrated in buffer, $50 \mathrm{mM}$ Tris- $\mathrm{HCl}, 100 \mathrm{mM}$ $\mathrm{NaCl}, \mathrm{pH}$ 8.0. Finally, the pure protein solution was concentrated and supplemented with $50 \%$ glycerol and stored at $-20^{\circ} \mathrm{C}$. SDS-PAGE was used to follow all the purification steps.

\section{Enzyme kinetics}

Enzyme activity was determined at $25^{\circ} \mathrm{C}$ by following the formation of $\mathrm{NAD}(\mathrm{P}) \mathrm{H}$ at $340 \mathrm{~nm}$ using a UV/vis Synergy 2 spectrophotometer (BioTek Winooski, VT, United States). An extinction coefficient of $5186 \mathrm{AU} \cdot \mathrm{M}^{-1}$ for $\mathrm{NAD}(\mathrm{P}) \mathrm{H}$ was used, this value due to considering our enzymatic experiment conditions $\mathrm{pH} 8.0,100 \mathrm{mM} \mathrm{NaCl}$ and $25{ }^{\circ} \mathrm{C}$, as described by Olavarria et $a .^{29}$. The substrates were titrated, after been neutralized to $\mathrm{pH} 7.0$, using the 6PGDH from Gluconobacter oxydans in the case of $\mathrm{NAD}^{+}$and 6PG and the G6PDH from Escherichia coli in the case of $\mathrm{NADP}^{+}$.

Progress curve analysis for Go6PGDH was performed for both $\mathrm{NAD}^{+}$and $\mathrm{NADP}^{+}$under initial velocity conditions, using different concentrations of the co-substrate 6PG. Our measurements were made before $5 \%$ of the initial substrate was consumed. To determine the kinetic parameters for $\mathrm{NADP}^{+}$, we used a concentration range of the cofactor between $33 \mu \mathrm{M}$ and $20 \mathrm{mM}$ at different fixed 6PG concentrations, ranging between 0.25 and $7 \mathrm{mM}$. To determine the kinetic parameters for $\mathrm{NAD}^{+}$, we used concentrations of the cofactor between $6 \mu \mathrm{M}$ to $5 \mathrm{mM}$ at fixed 6PG concentrations between 0.065 and $4 \mathrm{mM}$. The reaction buffer contained Tris- $\mathrm{HCl} 50 \mathrm{mM}, 10 \mathrm{mM} \mathrm{MgCl}$ and $100 \mathrm{mM} \mathrm{NaCl}$ at $\mathrm{pH}$ 8.0. The enzyme concentrations varied according to the substrate range used in the kinetic experiments. For low and high 6PG concentrations respectively, $20 \mathrm{nM}$ and $5 \mathrm{nM}$ of the enzyme was used. In the case of the mutants R31V, R31L and D33N, the kinetic parameters for $\mathrm{NAD}^{+}$and NADP ${ }^{+}$ were determined using $2 \mathrm{mM}$ of 6PG. The effect of the 3HIBA on the Ec6PGDH and Go6PGDH initial velocity was measured at saturating concentrations of substrates using $\mathrm{NADP}^{+}$and $\mathrm{NAD}^{+}$as cofactors, respectively. The 3HIBA was synthesized by basic hydrolysis of the ester Methyl (S)-(+)-3-hydroxy2 -methylpropionate in $5 \%$ of $\mathrm{NaOH}$ as excess. The product was frozen and lyophilised. The 3HIBADH salt was neutralised with $\mathrm{HCl}$ and purity corroborated by $\mathrm{H}^{1}$-NMR.

\section{X-Ray Crystallography}

After size-exclusion chromatography, Go6PGDH was con-

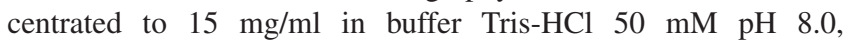
$100 \mathrm{mM} \mathrm{NaCl}$ and $2 \mathrm{mM}$ DTT. Sitting drop vapor diffusion experiments were performed by mixing $0.8 \mu \mathrm{L}$ protein solution and $0.8 \mu \mathrm{L}$ of crystallization condition and equilibrating against over $70 \mu \mathrm{L}$ mother solution at $18{ }^{\circ} \mathrm{C}$. After optimization, the crystallization condition contained $2 \mathrm{M}\left(\mathrm{NH}_{4}\right)_{2} \mathrm{SO}_{4}$ and $5 \%$ (v/v) 2-propanol and crystals appeared after 48 hours. For cryoprotection the same solution was supplemented with $25 \%(\mathrm{v} / \mathrm{v})$ glycerol and the sample cooled by plunging it into liquid nitrogen. Diffraction data were collected at the MX2 beamline at the UVX National Laboratory Light Synchrotron (Campinas, SP, Brazil) $^{30}$. Data were indexed and integrated with XDS software (http://xds.mpimf-heidelberg.mpg.de/, version March 15, 2019) $)^{31}$ and scaled and merged with Aimless $^{32}$, included in the CCP4 suite version 7.1 (https://www. ccp4.ac.uk//33. Phasing was carried out by molecular replacement with MOLREP (included in CCP4 suite version 7.1) ${ }^{34}$ using the homologous structure from Geobacter metallireducens (PDBid: 4E21). The model was iteratively refined using Coot version 0.8.9.3 (https://www2.mrc-lmb.cam.ac.uk/personal/ pemsley/coot/) ${ }^{35}$ and Phenix Refine from the PHENIX suite (version 1.18.2, https://www.phenix-online.org/ $)^{36}$. The geometry and stereochemistry of the structure was validated with MolProbity (http://molprobity.biochem.duke.edu/) ${ }^{14}$. The structure refinement statistics are shown in Table 1.

\section{Small Angle X-ray Scattering}

Small Angle X-ray Scattering data were collected at the beamline SAXS2 at the National Synchrotron Light Laboratory (Campinas, SP, Brazil), using the photon-counting Pilatus detector. A wavelength $\lambda=1.488 \AA$ was used with a sampledetector distance of $1000 \mathrm{~mm}$. A sample of Go6PGDH $3.2 \mathrm{mg} / \mathrm{ml}$ in Tris- $\mathrm{HCl} 50 \mathrm{mM} \mathrm{pH} 8.0,100 \mathrm{mM} \mathrm{NaCl}$ and $2 \mathrm{mM}$ DTT was irradiated for $3 \mathrm{~min}$ at room temperature. The SAXS Data were analyzed with the software ATSAS 3.0.1.1 ${ }^{37}$. The scattering of the corresponding buffer was subtracted to that of the protein solution and the resulting curve was analyzed with PRIMUS. The Radius of gyration was determined using the Guinier approximation and the pair distance distribution function $p(r)$ was evaluated using the program GNOM. Ab initio shape determination was performed using DAMMIN without any symmetry restriction. The structural superposition of the crystallographic structure of Go6PGDH and the SAXS envelope was performed using SUPCOMB. 


\begin{tabular}{|c|c|}
\hline & 6XEQ \\
\hline X-Ray source & LNLS MX2, Brazil \\
\hline Detector & PILATUS 2M \\
\hline Wavelength & $1.458660 \AA$ \\
\hline Resolution range $\AA$ & $100.3-3.2(3.37-3.2)$ \\
\hline Space group & $P 2_{1} 2_{1} 2_{1}$ \\
\hline Unit cell & $87.061 \AA 125.675 \AA 166.273 \AA 90^{\circ} 90^{\circ} 90^{\circ}$ \\
\hline Unique reflections & $30273(2601)$ \\
\hline Completeness (\%) & $97.65(85.54)$ \\
\hline Mean I/sigma(I) & $6.6(2.3)$ \\
\hline $\operatorname{CC}(1 / 2)$ & $0.978(0.757)$ \\
\hline Wilson B-factor & 38.3 \\
\hline R-merge & $0.092(0.327)$ \\
\hline R-meas & $0.130(0.462)$ \\
\hline R-pim & $0.092(0.327)$ \\
\hline Reflections used in refinement & $30098(2596)$ \\
\hline Reflections used for R-free & $1495(124)$ \\
\hline R-work & 0.246 \\
\hline R-free & 0.286 \\
\hline Number of non-hydrogen atoms & 9789 \\
\hline Number of macromolecules atoms & 9634 \\
\hline Numbers of solvents atoms & 155 \\
\hline Protein residues & 1271 \\
\hline RMS(bonds) & 0.004 \\
\hline RMS(angles) & 0.64 \\
\hline Ramachandran favored (\%) & 98.09 \\
\hline Ramachandran allowed (\%) & 1.83 \\
\hline Ramachandran outliers (\%) & 0.08 \\
\hline Rotamer outliers (\%) & 0.00 \\
\hline Clashscore & 7.62 \\
\hline Average B-factor & 37.61 \\
\hline Average B-factor for macromolecules & 37.76 \\
\hline Average B-factor for Solvent & 28.05 \\
\hline
\end{tabular}

Structural alignment and analysis

We searched in the Protein Data Bank for structures classified within the SCOPe family a.100.1.1, which contains 6PGDHs, $3 \mathrm{HIBADHs}$ and others $\beta \mathrm{HADH}$. To include members not assigned to the SCOPe classification, we used the 3D similarity function in the PDB, with a cut-off of $30 \%$ sequence identity ${ }^{38}$. The structures found are listen in Table 2 and we also incorporated propanoate dehydrogenase from the related SCOPe family a.100.1 to serve as outgroup (PDBid: 3QSG and 1I36). After 3D superposition using MultiSeq ${ }^{39}$, an evolutionary tree 
Table 2. Structures identified as part of the $\boldsymbol{\beta}$ HADH superfamily. The bold PDB codes were used to inference the structure-based phylogenetic tree of Figure 5.

\begin{tabular}{|c|c|c|c|c|}
\hline Reported Function in the PDB & PDB & Organism & Uniprot & Ligand \\
\hline 6-phosphogluconate dehydrogenase & 6FQX & Plasmodium falciparum & Q8IKT2 & \\
\hline 6-phosphogluconate dehydrogenase & $6 F Q Z$ & Plasmodium falciparum & Q8IKT2 & $6 P G$ \\
\hline 6-phosphogluconate dehydrogenase & 6FQY & Plasmodium falciparum & Q8IKT2 & $\mathrm{NADP}^{+}$ \\
\hline 6-phosphogluconate dehydrogenase & $4 G W K$ & Homo sapiens & P52209 & 3PG \\
\hline 6-phosphogluconate dehydrogenase & $2 J \mathrm{KV}$ & Homo sapiens & P52209 & $\mathrm{NADP}^{+}$ \\
\hline 6-phosphogluconate dehydrogenase & 4GWG & Homo sapiens & P52209 & \\
\hline 6-phosphogluconate dehydrogenase & $5 \cup Q 9$ & Homo sapiens & P52209 & $8 \mathrm{HS}$ \\
\hline 6-phosphogluconate dehydrogenase & 2ZYG & Klebsiella pneumoniae & C4XAX8 & \\
\hline 6-phosphogluconate dehydrogenase & 3FWN & Escherichia coli & P00350 & ATR/6PG \\
\hline 6-phosphogluconate dehydrogenase & $2 Z Y A$ & Escherichia coli & P00350 & $6 P G$ \\
\hline 6-phosphogluconate dehydrogenase & $2 Z Y D$ & Escherichia coli & P00350 & Glucose \\
\hline 6-phosphogluconate dehydrogenase & 1PGJ & Trypanosoma brucei & P31072 & \\
\hline 6-phosphogluconate dehydrogenase & 2IYO & Lactococcus lactis & P96789 & $6 P G$ \\
\hline 6-phosphogluconate dehydrogenase & $2 \mathrm{IZ1}$ & Lactococcus lactis & P96789 & ATR \\
\hline 6-phosphogluconate dehydrogenase & $2 \mathrm{IZO}$ & Lactococcus lactis & P96789 & $\mathrm{NADP}^{+}$ \\
\hline 6-phosphogluconate dehydrogenase & 2IYP & Lactococcus lactis & P96789 & NADP/5RP \\
\hline 6-phosphogluconate dehydrogenase & $2 W 90$ & Geobacillus stearothermophilus & I3NI58 & $6 P G$ \\
\hline 6-phosphogluconate dehydrogenase & $2 W 8 Z$ & Geobacillus stearothermophilus & I3NI58 & $6 P G$ \\
\hline 6-phosphogluconate dehydrogenase & $2 \mathrm{P} 4 \mathrm{Q}$ & Saccharomyces cerevisiae & P38720 & Citrate \\
\hline 6-phosphogluconate dehydrogenase & 1PGO & Ovis aries & P00349 & NADPH \\
\hline 6-phosphogluconate dehydrogenase & 1PGP & Ovis aries & P00349 & $6 P G$ \\
\hline 6-phosphogluconate dehydrogenase & 2PGD & Ovis aries & P00349 & \\
\hline 6-phosphogluconate dehydrogenase & 1PGQ & Ovis aries & P00349 & \\
\hline 6-phosphogluconate dehydrogenase & $1 P G N$ & Ovis aries & P00349 & $\mathrm{POP} / \mathrm{NBP}$ \\
\hline 6-phosphogluconate dehydrogenase & 4E21 & Geobacter metallireducens & Q39SD5 & \\
\hline 6-phosphogluconate dehydrogenase & 6VPB & $\begin{array}{l}\text { Gluconacetobacter } \\
\text { diazotrophicus }\end{array}$ & А9H324 & \\
\hline 6-phosphogluconate dehydrogenase & 6XEQ & Gluconobacter oxydans & G5EBD7 & \\
\hline 6-phosphogluconate dehydrogenase & 4GBJ & Dyadobacter fermentans & C6VV20 & \\
\hline 3-hydroxyisobutyrate dehydrogenase & $3 G 00$ & Salmonella typhimurium & Q8ZMG4 & $\mathrm{L}(+)$ Tartaric acid \\
\hline Succinic semialdehyde reductase & 3PDU & Geobacter sulfurreducens & Q74DE4 & $\mathrm{NADP}^{+}$ \\
\hline 3-Hydroxyisobutyrate dehydrogenase & 2I9P & Homo sapiens & P31937 & NAD \\
\hline 3-Hydroxyisobutyrate dehydrogenase & $2 \mathrm{CVZ}$ & Thermus thermophilus HB8 & Q5SLQ6 & $\mathrm{NADPH}$ \\
\hline 3-Hydroxyisobutyrate dehydrogenase & 1WP4 & Thermus thermophilus HB8 & Q5SLQ6 & $\mathrm{NADPH}$ \\
\hline 3-Hydroxyisobutyrate dehydrogenase & 5JE8 & Bacillus cereus & Q81DR6 & $\mathrm{NAD}^{+}$ \\
\hline Tartronate semialdehyde reductase & 1VPD & Salmonella typhimurium & Q8ZLV8 & $\mathrm{L}(+)$ Tartaric acid \\
\hline Hydroxymethylglutarate dehydrogenase & $3 C K Y$ & Eubacterium barkeri & Q0QLF5 & \\
\hline L-Serine dehydrogenase & зовв & Pseudomonas aeruginosa & Q9I5I6 & \\
\hline L-Serine dehydrogenase & 3WS7 & Pyrobaculum calidifontis & A3MU08 & $\mathrm{NADP}^{+}$ \\
\hline L-Serine dehydrogenase & $5 X V H$ & Pyrobaculum calidifontis & A3MU08 & $\begin{array}{l}\mathrm{NADP}^{+} / \mathrm{L}(+) \text {-Tartaric } \\
\text { acid }\end{array}$ \\
\hline 2-hydroxypropylphosphonate reductase & 5U5G & Pseudomonas syringae & I6R485 & $\mathrm{NADP}^{+}$ \\
\hline
\end{tabular}


was built from atomic distances (RMSDs) and the fraction of equivalent residues from the superimposed tertiary structures, using the method of Johnson et $a .^{40}$. From the RMSD values obtained for each pair of structures in the prior structural alignment, a matrix of SRMS was built:

$$
S R S M=1-R M S D / 3.5
$$

For that, the number of topological equivalences for two structures was determined, given by the number of overlays per residue whose homologous positions along the structural alignment had an RMSD value of less than $3.5 \AA$. In this way the fractional topological equivalence by pairs (PFTE) was calculated, dividing the number of topological equivalences by the length of the minor structure compared. Considering these two values, the structural evolutive distance (D) was calculated by the following equation:

$$
D=-100 \ln \left(w_{1} P F T E+w_{2} S R M\right)
$$

where $\mathrm{w} 1+\mathrm{w} 2=1$ and these values are calculated as follows:

$$
\begin{gathered}
w_{1}=(1-P F T E)+(1-S R M S) / 2 \\
w_{2}=(P F T E+S R M S) / 2
\end{gathered}
$$

Finally, with the D values represented in a distance matrix obtained for each pair of structures, a dendrogram was represented using the neighbor-joining method available in the T-rex web server ${ }^{41}$.

For the analysis of quaternary structure in short-chain 6PGDHs we used the Protein interfaces, surfaces and assemblies' service PISA at the European Bioinformatics Institute: https://www.ebi. ac.uk/pdbe/pisa/ ${ }^{42}$.

\section{Multiple sequences alignment and phylogenetic analysis}

We first searched the TrEMBL (UniProtKB) database for Ec6PGDH and Go6PGDH homologs that have been kinetically characterized using $\mathrm{NAD}^{+}$or $\mathrm{NADP}^{+}$as the cofactor ${ }^{43}$. Then, we performed an exhaustive search of sequences with one or two hemi-domains that possess the 6PGDH catalytic motif (identified in the superfamily structural tree) but containing different motifs in the $\beta 2-\alpha 2$ loop. We retrieved a total of $836 \mathrm{PGDH}$ sequences. To align these sequences using Clustal $\mathrm{X}^{44}$, we created a structural profile based on an alignment of 6PGDHs from E. coli and G. metallireducens, (PDB identifiers 3FWN and 4E21 respectively). Using this structural profile, 10 sequences with one or two hemi-domains in the $\mathrm{C}$-terminal region were aligned, generating a second profile. The remaining sequences were aligned against the second profile, using the BLOSUM62 substitution matrix and iterating each step of the alignment. Misaligned positions were manually corrected.

The phylogenetic tree of the aligned 6PGDH sequences was inferred using MrBayes version 3.1.2. as the outgroup. We used WAG as the evolutionary model of amino acid replacement for globular proteins ${ }^{46}$, and a gamma-shaped rate variation across sites was assumed with a proportion of invariable sites. The number of generations was adjusted to 10 million trees with a sampling frequency every 1000 generations and $20 \%$ of generated trees burned. The average standard deviation of split frequencies was less than 0.01 upon convergence.

\section{Statistical analysis}

The statistical analysis was performed for the enzyme kinetic experiments using the GraphPad Prism version 8 (https://www. graphpad.com/). To the different enzymatic progress curves, a Michaelis-Menten model was fitted to the data. To the tertiary graphs (kinetic parameters versus substrate concentration), a hyperbolic model was fitted to the $k_{c a t}$ dependence with 6PG concentration. A model of hyperbolic decay with an intersection in the $\mathrm{y}$-axis was fitted to the $\mathrm{K}_{\mathrm{M}}$ behaviour with 6PG concentration. We use a confidence level of $95 \%$ computed with an asymmetrical model (profile-likelihood) for all the cases. The GraphPad Prism software provided the statistical analysis.

\section{Results}

The crystal structure of Go6PGDH: features of a tetrameric assembly

The asymmetric unit of the crystal contains four monomers of Go6PGDH. The overall fold of each shows an elongated monomer, as illustrated in Figure 2A. Three regions can be distinguished: The N-terminal domain, which adopts the Rossmann-fold, followed by an extension made of a threestranded $\beta$ sheet topped by three helices (we name this extension the $3 \beta 3 \alpha$ unit). The central part of the protein folds as a helical domain, with a long helix $(\alpha 9)$ surrounded by pairs of shorter $\beta$-helices, two of them $(\alpha 10$ and $\alpha 11)$ distal to the N-terminal domain and two of them ( $\alpha 12$ and $\alpha 13)$ proximal to it. Distal and proximal $\alpha$-helices are connected by a connecting loop (residues 265-276) that is disordered in the crystal. The third region of the Go6PGDH monomer is the C-terminal $\alpha$-helix $(\alpha 14)$, protruding from the body of the helical domain. The Go6PGDH tetramer assembles as a dimer of dimers, in which all four subunits contact each other, with the largest interface formed by the helical domains within the dimer (Figure 2B). In this interface, two $\alpha 9$ helices contact each other in a nearly antiparallel configuration, with the loops between the $\alpha 10$ and $\alpha 11$ proximal helices are flanking each other. Within the dimer, the $\alpha 10$ and $\alpha 11$ pair of distal helices of one monomer slot in a cavity on the surface of the $3 \beta 3 \alpha$ unit of the other monomer (Figure 2A). The active sites of the two subunits in the dimer face outwards. Two of these elongated dimers interact through a smaller interface in which the pairs of proximal helices $\alpha 12$ and $\alpha 13$ form an anti-parallel $2+2$ helix-bundle and the C-terminal helix $\alpha 14$ reaches across the $\alpha 11$ and $\alpha 12$ helices of a third monomer (Figure 2C). According to SAXS data, a tetrameric arrangement is present in solution as well (Figure 3). The scattering curve and distance distribution function (Figure $3 \mathrm{~A}$ and Figure 3B) revealed a radius of gyration and maximum distance distribution of 3.8 and $11.9 \mathrm{~nm}$, respectively. The superposition of our X-ray structure and the $a b$ initio model built from the $P(r)$ distribution curve shows that the dimer-dimer interface seen in the crystal is preserved in solution (Figure 3C). 
The first structure of the tetrameric 6PGDH to be reported in the PDB was the 6PGDH from Geobacter metallireducens (Gm6PGDH, PDB: 4E21, $\mathrm{rmsdC}_{\alpha}=$ over $1.41 \mathrm{C}_{\alpha \mathrm{s}}$ compared with Go6PGDH), which we used as the search model for Molecular Replacement. Although 4E21 shows a dimer in the asymmetric unit, a tetramer equivalent to our Go6PGDH can be generated by crystallographic symmetry. Furthermore, while we were preparing this report, the X-ray structure of $G d 6 \mathrm{PGDH}$ was disclosed (PDBid, $\mathrm{rmsdC}_{\alpha}=1.02$ compared with Go6PGDH) also showing a dimer in the asymmetric unit. Likewise, a tetramer that conserves the same features described for Go6PGDH can be generated by applying a crystallographic twofold. In fact, analysis by PISA indicated a buried surface area compatible with tetrameric association for all three short-chain 6PGDHs (Figure 3D). However, Gd6PGDH was reported to behave as a dimer in solution, according to native gel electrophoresis $^{2}$. Structural superposition of Gm6PGDH and
Go6PGDH (Figure 4A, left) shows slight changes in the relative orientation of the $\mathrm{N}$-terminal domain respect to the helical domain, and of the C-terminal $\alpha$-helix with respect to the latter.

\section{Superfamily-level relationships: architectural changes} of 6PGDHs

We compared the structures of the tetrameric enzymes Gm6PGDH, Go6PGDH and Hs3HIBADH and the dimeric Ec6PGDH (Figure 4). In the N-terminal domain, we found differences that affect subunit interactions. In the $3 \beta 3 \alpha$ unit, the loop formed by the residues 160 to 182 of $G o 6 \mathrm{PGDH}$ is absent in $H s 3 \mathrm{HIBADH}$ and shorter in Ec6PGDH (Figure 4A and Figure 4C). This loop covers most of the surface of the distal helices from the partner subunit within the dimer. On the other hand, the loop $\beta 2-\alpha 2$ is a short connector whose sequence features are related to cofactor specificity (see below). The alignment (Figure 4C) showed that it harbors an NR motif in
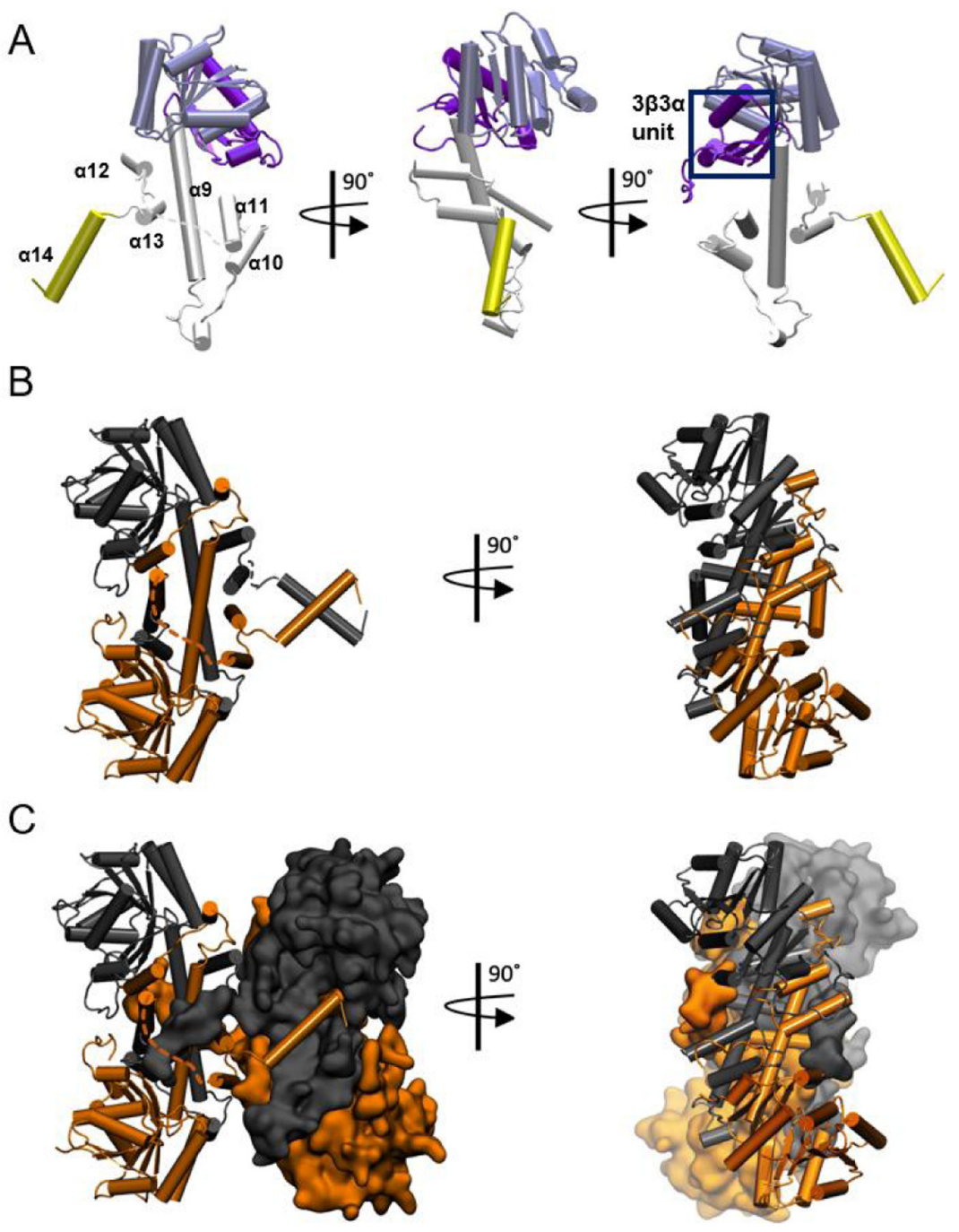

Figure 2. Tertiary and quaternary structure of Go6PGDH. (A) the monomeric structure. The N-terminal domain is colored violet and the $3 \beta 3 a$ unit is purple. The helical domain is colored light gray and the C-terminal $a$-helix in yellow; (B) Two monomers packed through the more extended interface; $(\mathbf{C})$ The tetrameric structure. The second dimer is represented as surface. 
A

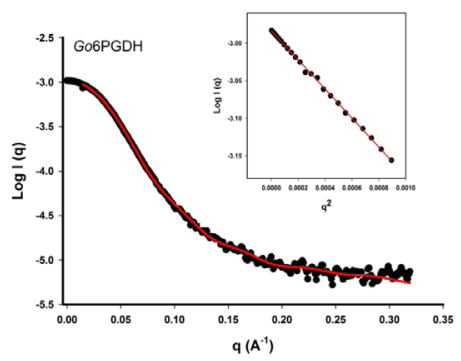

B

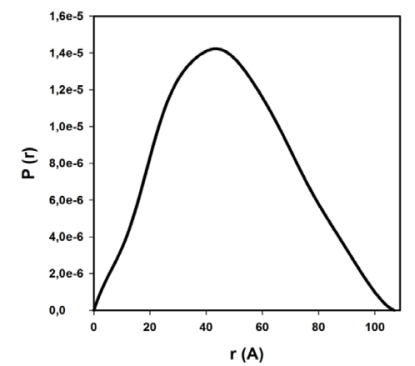

C
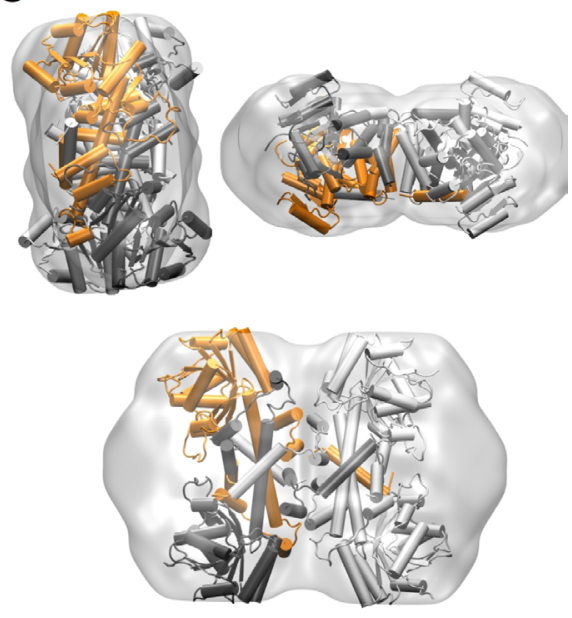

$\mathrm{D}$
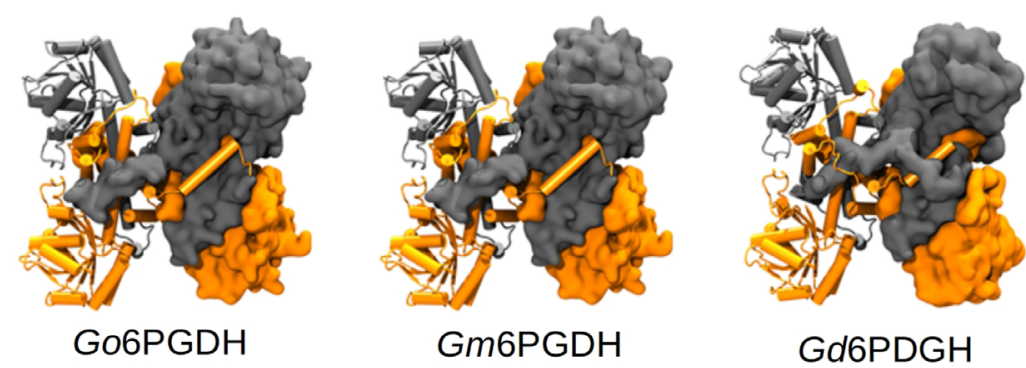

Gd6PDGH

\begin{tabular}{|c|c|c|c|c|c|}
\hline & & $\begin{array}{c}\text { Surface } \\
\text { Area } \\
\AA^{2}\end{array}$ & $\begin{array}{c}\text { Buried Area } \\
\AA^{2}\end{array}$ & $\begin{array}{c}\Delta \mathbf{G}^{\text {int }} \\
\mathrm{kcal} / \mathrm{mol}\end{array}$ & $\begin{array}{c}\Delta \mathbf{G}^{\text {diss }} \\
\mathrm{kcal} / \mathrm{mol}\end{array}$ \\
\hline \multirow{2}{*}{ Go6PGDH } & $\overline{\text { Dimer }}$ & 29890 & 7160 & -63 & 64 \\
\hline & Tetramer & 49190 & 24600 & -186 & 65 \\
\hline \multirow{2}{*}{ Gm6PGDH } & Dimer & 28190 & 8260 & -50 & 60 \\
\hline & Tetramer & 44460 & 28440 & -173 & 81 \\
\hline Gd6PGDH & $\begin{array}{l}\text { Dimer } \\
\text { Tetramer }\end{array}$ & 27090 & $\begin{array}{l}7360 \\
25750\end{array}$ & $\begin{array}{l}-62 \\
-215\end{array}$ & $\begin{array}{c}64 \\
140\end{array}$ \\
\hline
\end{tabular}

Figure 3. SAXS structure of the apo GoPGDH and quaternary structures of short-chain 6PGDHs. (A) SAXS data of apo Go6PGDH. The inset shows the linear fitting of q values $<1.3 / R_{\mathrm{q}}$ according to the Guinier approximation. (B) Interatomic distance distribution function $p(r)$ of Go6PGDH. (C) Different side views of the Ab initio shape model of Go6PGDH superimposed to the crystal structure of Go6PGDH. D (Above) Tetrameric structure of Go6PGDH, Gm6PGDH and Gd6PGDH. For each protein dimers are represented in cartoon and surface. (Below) Surface, buried area and $\Delta \mathrm{G}$ for interaction and dissociation for dimer an tetramer for each protein, determined by PISA are showed.

the case of the $\mathrm{NADP}^{+}$-dependent Ec6PGDH, a DV motif in the $\mathrm{NAD}^{+}$-dependent $H s 3 \mathrm{HIBADH}$, and the mixed sequence $\mathrm{DR}$, in Go6PGDH.

However, the main architectural differences are found in the helical domain and are associated with a remodeling of the active site. In the case of $H s 3 \mathrm{HIBADH}$, the C-terminal $\alpha$-helix packs against the long helix (structurally equivalent to Go6PGDH $\alpha 9$ ), while the segment connecting distal and proximal helices forms part of the substrate binding site (Figure 4D). In the case of the dimeric Ec6PGDH, the C-terminal $\alpha$-helix of hemidomain 1 moves away from the long helix allowing the linkage with hemidomain 2, while the segment connecting distal and proximal helices is displaced away from the active site permitting the insertion of the C-terminal $\alpha$-helix to the neighboring subunit (Figure 4E). In hemidomain 2, which does not contribute to the active site, the C-terminal $\alpha$-helix is swung away by a further $65^{\circ}$ with respect to the position seen in hemidomain 1 , enabling the orientation required for insertion into the neighboring subunit, while the segment connecting distal and proximal helices is packed against the long helix (Figure 4F). Comparing Go6PGDH to Ec6PGDH, while the C-terminal $\alpha$-helix superposes well with that from hemidomain 2 , the segment connecting distal and proximal helices takes on a role equivalent to the one seen in hemidomain 1 (Figure 4B and Figure 4G). Comparing Go6PGDH to Hs3HIBADH, it is noteworthy that the C-terminal $\alpha$-helix in the former occupies a location in the neighboring subunit equivalent to that 


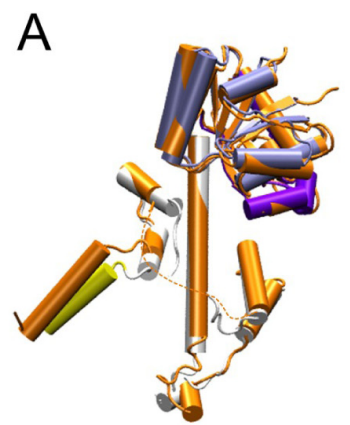

B
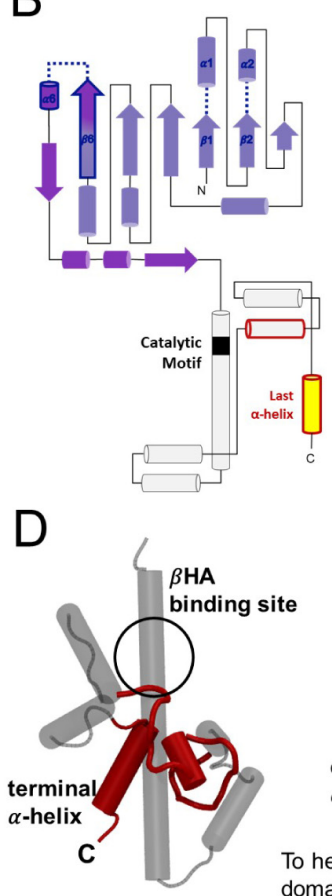

Hs3HIBADH
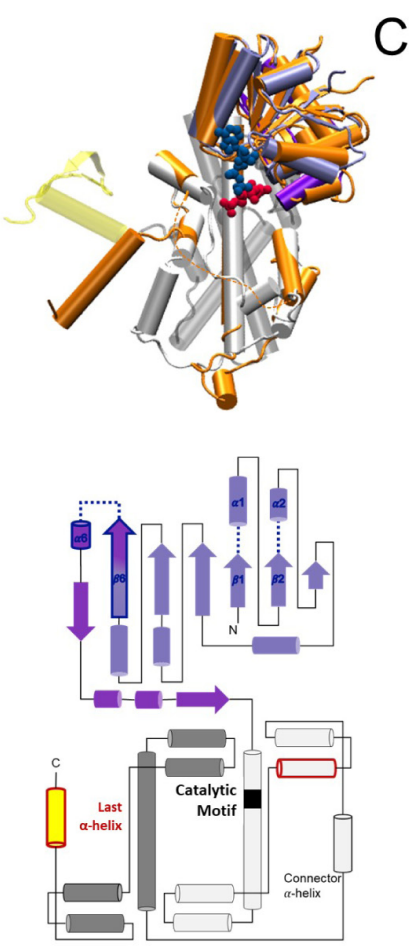

E

E

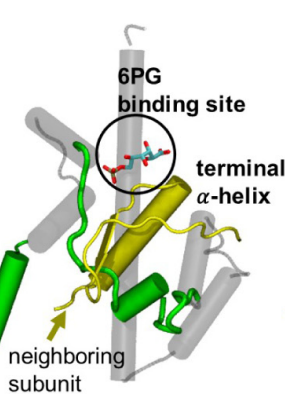

Ec6PGDH

hemidomain 1
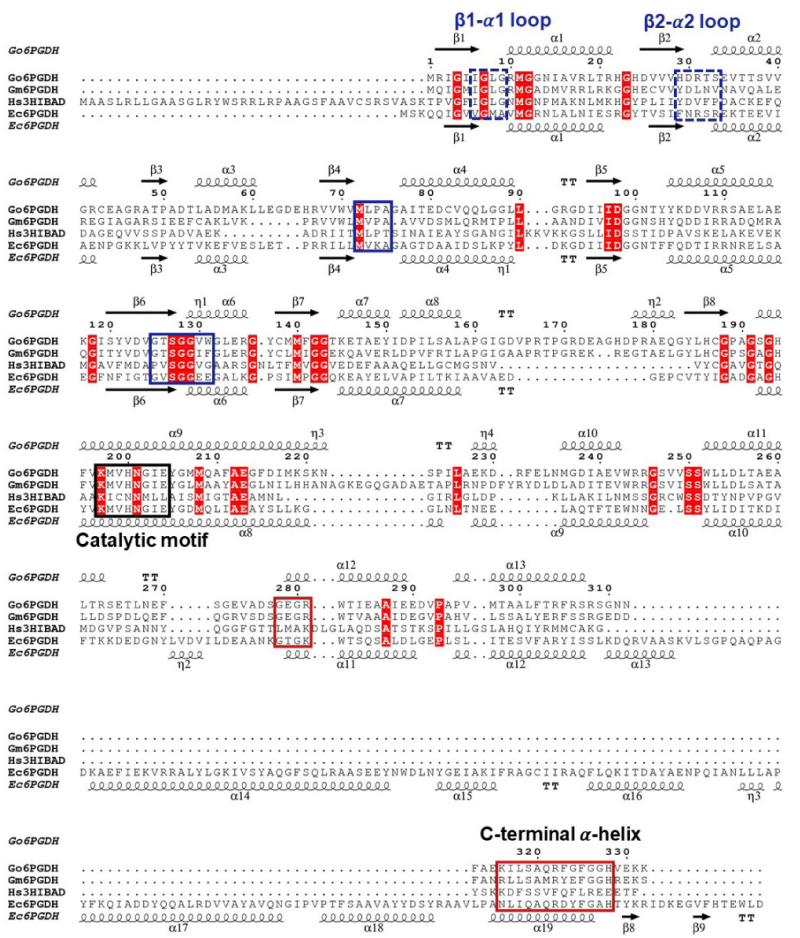

F

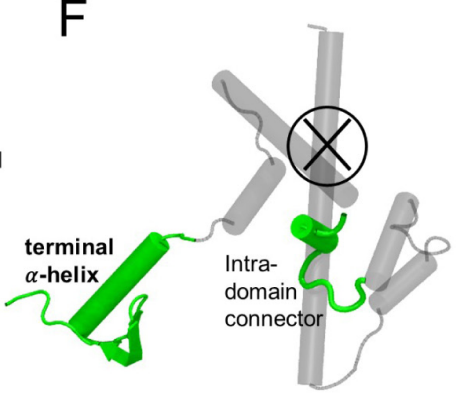

Ec6PGDH

hemidomain 2
G

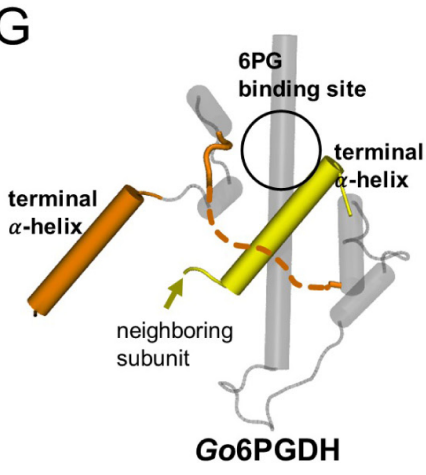

Figure 4. Topology, structural superposition and sequence alignment of tetrameric and dimeric 6PGDHs. (A) Monomers superposition of Go6PGDH (orange) with Gm6PGDH (left) and Ec6PGDH (right). The last two structures are colored following the segmentation depicted in Figure 2A (hemidomain 2 of Ec6PGDH is represented transparent). (B) Topology diagrams of Go6PGDH (left) and Ec6PGDH (right), colored following the segmentation depicted in Figure 2A. Note that the first strand in the $\beta 3 \alpha 3$ unit results from the elongation of the $6^{\text {th }}$ canonical Rossmann strand. (C) The loop encircled shows variable length when comparing different. Identic residues are colored in red. Blue dotted rectangles denote the $\beta 1-\alpha 1$ and $\beta 2-\alpha 2$ loops that interact with the adenine-ribose region of the cofactor. Blue and red rectangles indicate the zones of the interaction with the rest of the cofactor and 6PG, respectively. In a black rectangle is showing the catalytic motif. The secondary structure of Go6PGDH and Ec6PGDH is shown as a reference. Note that the helical domains of the tetrameric representatives aligned with Ec6PGDH hemidomain 1, except for the C-terminal $a$-helix, which aligned with that of hemidomain 2. (D) Hs3HIBADH. (E) Hemi-domain 1 (F) 2 from Ec6PGDH and (G) Go6PGDH . In each structure, the segment connecting distal and proximal helices and the C-terminal $a$-helix are labeled and colored to highlight their different orientations. Note that the penetrating $\alpha$-helix (yellow) occupy an equivalent location as the C-terminal $\alpha$-helix of Hs3HIBADH but in the opposite orientation.

of the C-terminal $\alpha$-helix in the helical domain of the latter. However, the C-terminal $\alpha$-helices of these proteins adopt opposite orientations to compound the tertiary structure, and thus it cannot be considered a true case of a minimalist domain swapping. These results reveal that the tetrameric structure of Go6PGDH is indispensable for full interactions at the 6PG binding site.
In order to have a wider landscape of the structural similarity at the superfamily level, we generated a phylogenetic tree based on the structural superposition of the monomeric unit of superfamily members with available crystal structures (Table 2). As shown in Figure 5, dimeric and tetrameric 6PGDHs constitute a clade, having the same catalytic motif KMXHNXXE (Figure $5 \mathrm{~B})^{47}$, while the rest of $\beta \mathrm{HADHs}$ form a paraphyletic 
A

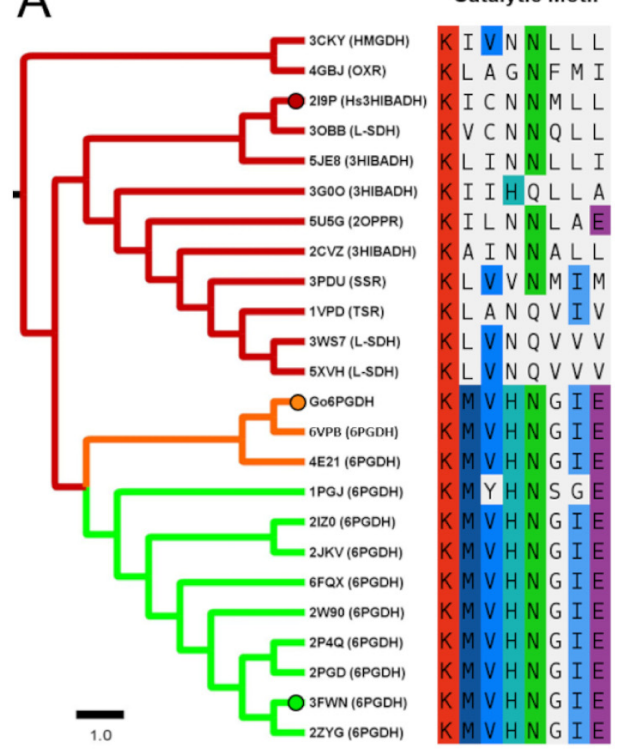

B
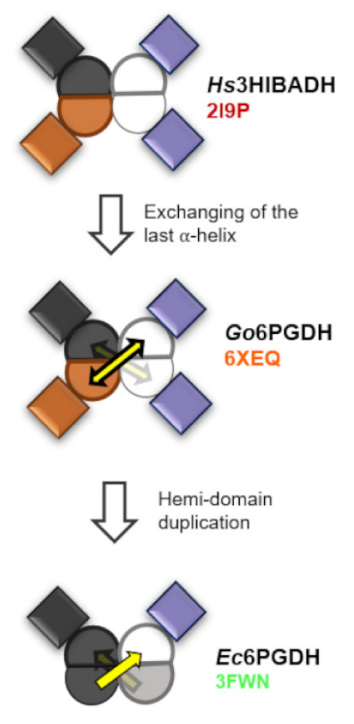

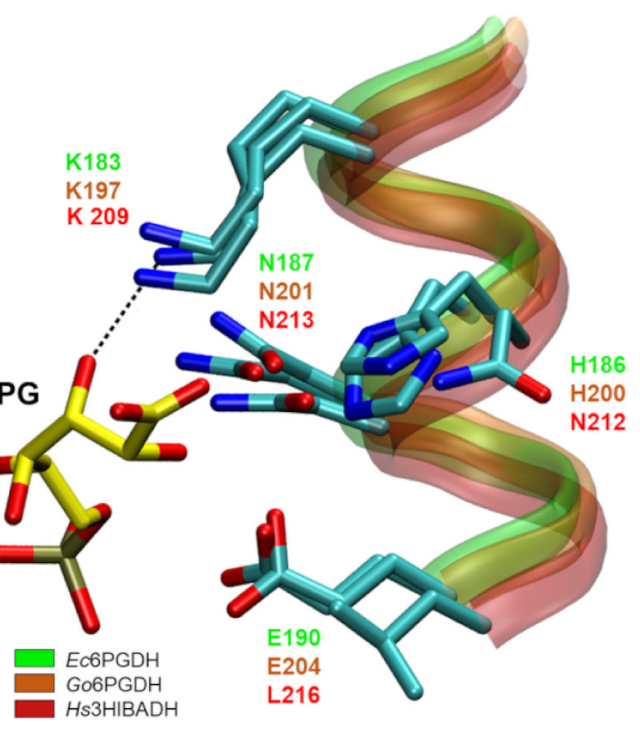

Figure 5. Structure-based phylogenetic tree of the $\boldsymbol{\beta}$ HADH superfamily. (A) Left, neighbor-joining dendrogram based on RMSD and residue conservation after 3D alignment of selected PDBs ${ }^{40}$, listed in Table 2. Abbreviations: L-SDH (L-serine dehydrogenase), TSR (tartronate semialdehyde reductase), SSR (succinic semialdehyde reductase), HMGDH (hydroxymethylglutarate dehydrogenase), 2OPPR (2-hydroxypropylphosphate reductase), OXR (putative oxidoreductase). Branches of the tree colored according to dimeric 6PGDHs (green), tetrameric 6PGDHs (orange) and other $\beta$ HADHs (red). Midle, correlated sequence alignment obtained from the structural superposition used to build the tree of Figure 5. Orange and green branch posses the conserved motif KMXHNGXE. Right, simplified schematization of the three oligomerization kinds observed in the superfamily. Domains are represented by squares ( $\mathrm{N}$-terminal domain) and semicircles (helical domain). The yellow arrows represent the C-terminal $\alpha$-helix that is exchanged between neighboring active sites. Entire subunits are colored in orange and dark gray. (B) 3D view of the segment of the a-helix bearing the catalytic motif in the PDB structures 2I9P, 6EXQ and 3FWN. Residues involved in the interaction with 6PG of Ec6PGDH, and the homologous residues in the rest of the structures are shown.

group. The exchange of the C-terminal $\alpha$-helix between subunits is the synapomorphic feature that distinguished 6PGDHs, while the tetrameric state with no structural elements shared between subunits is the symplesiomorphic trait shown by the rest of $\beta$ HADHs. Thus, the short-chain 6PGDHs can be viewed as intermediate in the former evolutionary pathway proposed by Andreeva and Murzin 2006, from $\beta$ HADHs towards dimeric 6PGDHs (Figure 5A, schematic representation) ${ }^{10}$.

The hypothesis that tetrameric 6PGDHs were intermediate in the evolutionary pathway towards dimeric 6PGDHs would imply increasing substrate selectivity at play in the $\beta \mathrm{HA}$ binding site. To test this idea, we evaluated the activity of Go and Ec6PGDH against the substrate $3 \mathrm{HIBA}^{48}$. Neither enzyme is active against $3 \mathrm{HIBA}$, but Go6PGDH and not Ec6PGDH is inhibited by it, as illustrated in Figure 6. Although the effect occurs in a concentration range that is not physiological, it suggests that the 6PG binding site is more promiscuous in tetrameric 6PGDHs than in the dimeric ones.

Family-level relationships: phylogeny and signatures of dinucleotide specificity

A phylogenetic reconstruction was generated by using a broad sample of sequences from tetrameric and dimeric 6PGDHs from a diverse range of eukaryotic, bacterial and archaeal lineages. Short-chain and long-chain 6PGDHs form basally separated clusters. In the branch of dimeric 6PGDHs (Figure 7, green

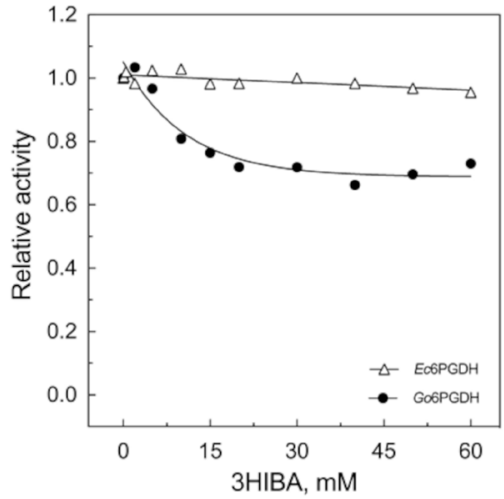

Figure 6. Effect of the 3HIBA on the activity of Go6PGDH and Ec6PGDH. Data is available in 48.

subdivision) we found mainly bacteria and eukaryotes from different phyla. Among the bacterial lineages three different clades stand out: $b_{1}$. cluster mainly made of firmicutes; $b_{2}$. cluster containing mainly cyanobacteria; and $b_{3}$. $\alpha$-proteobacteria. Among the eukaryotic representatives, we also found three monophyletic groups: $e_{l}$. opisthokonta: fungi (ascomycetes and basidiomycetes) and animals; $e_{2}$. cluster mainly made of plants; and $e_{3}$. a second ascomycetes group plus euglenozoa. The clades $b_{1}$ and $e_{1}$ constitute a bigger group, named $F O$ 


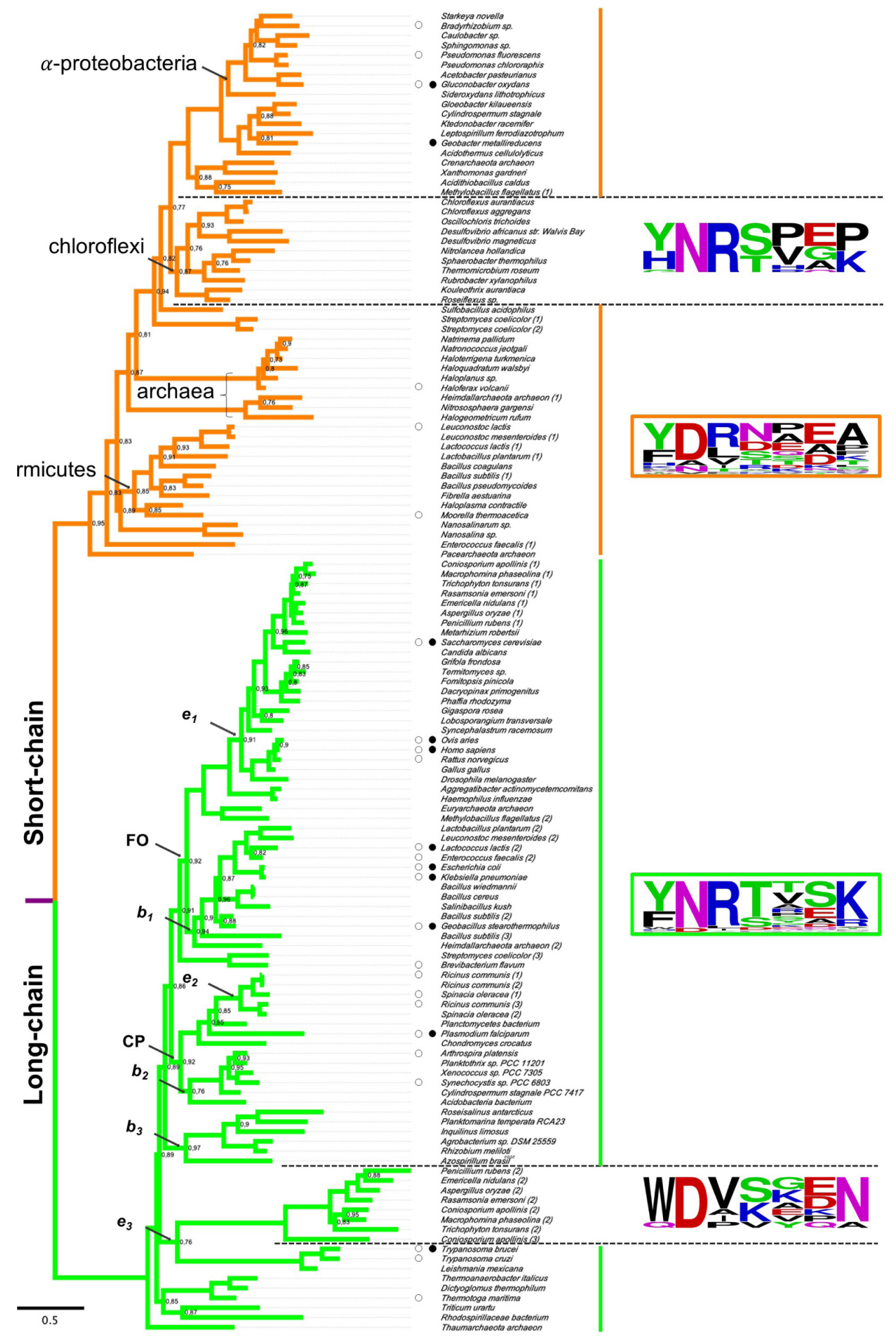

Figure 7. Bayesian phylogenetic tree of the 6PGDH family. The root was set by using 3HIBADHs sequences as the outgroup. The reported oligomeric state is consistent with the most basal division in tetrameric and dimeric branches. The sequences in the tetrameric branch have an average extension of 339 amino acids (indicating a single hemi-domain), and in the dimeric branch the average is 472 (indicating a duplicated hemi-domain). Nodes are labelled with the posterior probability whenever this value was lower than 1. Clades labeled by arrows are defined in Results. At the left side of the species name, white circles indicate that cofactor specificity has been reported, and black circles that the structure is known. At the right side, sequence logos are used to show the sequence conservation of the $\beta 2-\alpha 2$ loop (actual sequences of these segments are availble in Zenodo depository ${ }^{43}$ ). The sequence logo starts from the aminoacid 29 to 35 , considering the position in Go6PGDH. Note that in each subfamily, a monophyletic group showing a changed pattern was found. 
(firmicutes + opisthokonta). Likewise, the $b_{2}$ and $e_{2}$ clades compose the group $C P$ (cyanobacteria + plant). Remarkably, although the $\alpha$-proteobacteria clade is a sister group to the superclade $F O+C P$, there is a eukaryotic clade lying closer to the root, namely $e_{3}$. Meanwhile, in the branch of tetrameric 6PGDHs (Figure 7, orange subdivision) we found sequences from bacteria and archaea. Among the bacterial representatives, three groups were the most clearly differentiated: a cluster mainly made of $\alpha$-proteobacteria, a cluster mainly made of chloroflexi, and a cluster mainly made of firmicutes (lying closer to the root). Although several archaeal sequences from different phyla were interspersed in different branches, only one group congregated a coherent lineage: the order Halobacteriales.

In the branch of dimeric 6PGDHs (Figure 7, green subdivision), reports on kinetic characterization and crystal structures were found mostly for representatives of the $F O$ clade. For the $C P$ clade, kinetic information has been reported for several members, but a crystal structure was available only for Plasmodium 6PGDH (a close relative of cluster $e_{2}$ ). However, for $\alpha$-proteobacteria and the ascomycota from clade $e_{3}$, neither kinetic nor crystal structures reports were found. Considering cofactor specificity, the dimeric 6PGDHs have been mostly characterized for the use of $\mathrm{NADP}^{+}$, showing $\mathrm{K}_{\mathrm{M}}$ values between 2 and $258 \mu \mathrm{M}$ (Table 3). In the cases of $\mathrm{NAD}^{+}$characterization the $\mathrm{K}_{\mathrm{M}}$ values varied between about 4 and $9 \mathrm{mM}$, indicating that they have preference or selectivity towards $\mathrm{NADP}^{+}$. This trend is consistent with the presence of a strongly conserved $\mathrm{NRX}_{3} \mathrm{~K}$ motif in the $\beta 2-\alpha 2$ loop of most dimeric 6PGDHs (Figure 7). Interesting exceptions were found, especially in the case of the ascomycota 6PGDHs from clade $e_{3}$, which possessed a $\mathrm{DVX}_{3} \mathrm{~N}$ motif ${ }^{43}$. The change of $\mathrm{NR}$ motif to DV suggested a preference for $\mathrm{NAD}^{+}$.

Among the tetrameric 6PGDHs (Figure 7, orange subdivision), information on kinetics and structure is more limited. Enzymes from firmicutes, proteobacteria and archaea have been kinetically characterized, showing that in general, $\mathrm{NAD}^{+}$is the preferred cofactor (Table 3). Interestingly, only the $\alpha$-proteobacteria clade, to which Go6PGDH belong, showed a conserved DR

Table 3. Reported kinetic parameters of members of the 6-phosphogluconate dehydrogenase family. *: Specific activity is reported.

\begin{tabular}{|c|c|c|c|c|c|c|}
\hline \multirow[t]{2}{*}{ Protein } & \multicolumn{2}{|c|}{ NADP $^{+}$} & \multicolumn{2}{|c|}{$\mathrm{NAD}^{+}$} & \multirow{2}{*}{$\begin{array}{c}\mathrm{NAD}^{+} / \mathrm{NADP}^{+} \\
{\left[k_{\text {cat }} / \mathrm{K}_{\mathrm{M}}\right]^{\mathrm{NAD}+} /\left[k_{c a t} / \mathrm{K}_{\mathrm{M}}\right]^{\mathrm{NADP}+}}\end{array}$} & \multirow[b]{2}{*}{ Reference } \\
\hline & $\mathbf{K}_{M}(\mu \mathrm{M})$ & $k_{\text {cat }}\left(\mathbf{s}^{-1}\right)$ & $\mathbf{K}_{M}(\mu \mathrm{M})$ & $k_{\text {cat }}\left(\mathbf{s}^{-1}\right)$ & & \\
\hline \multicolumn{7}{|l|}{ Dimeric 6PGDH } \\
\hline Enterococcus faecalis & 15.0 & & & & & 49 \\
\hline Thermotoga maritima & 5.0 & 17.6 & 4,300 & 23.3 & $6.7 \times 10^{-4}$ & 22 \\
\hline Trypanosoma cruzi & 5.9 & 98.0 & & & & 50 \\
\hline Trypanosoma brucei & 1.5 & 27.0 & & & & 50 \\
\hline Ovis aries & 2.0 & 9.3 & & & & 19 \\
\hline Geobacillus stearothermophilus & 3.4 & 22.1 & & & & 51 \\
\hline Klebsiella pneumoniae & 118.0 & $13.0 \mathrm{U} / \mathrm{mg}$ * & & & & 17 \\
\hline Escherichia coli & 49.0 & 21.0 & & & & 17 \\
\hline Homo sapiens & 6.9 & 21.4 & & & & 18 \\
\hline Plasmodium falciparum & 9.0 & 7.6 & & & & 18 \\
\hline Synechocystis PCC 6803 & 58.0 & 51.0 & 4,460 & 4.89 & $1.3 \times 10^{-3}$ & 52 \\
\hline Arthrospira platensis & 19.0 & 16.6 & & & & 52 \\
\hline Spinacia oleracea chloroplastic & 6.0 & & & & & 23 \\
\hline Saccharomyces cerevisiae & 35.0 & & & & & 53 \\
\hline Ricinus communis (plastidial) & 5.4 & & & & & 54 \\
\hline Ricinus comunis (cytosolic) & 4.1 & & & & & 54 \\
\hline Brevibacterium flavum & 36.0 & & & & & 55 \\
\hline Rattus norvegicus & 258.0 & $10.8 \mathrm{U} / \mathrm{mg}^{*}$ & & & & 56 \\
\hline Lactococcus lactis & 1.9 & $38.3 \mathrm{U} / \mathrm{mg}^{*}$ & & & & 21 \\
\hline
\end{tabular}




\begin{tabular}{|c|c|c|c|c|c|c|}
\hline \multirow[t]{2}{*}{ Protein } & \multicolumn{2}{|c|}{ NADP $^{+}$} & \multicolumn{2}{|c|}{$\mathrm{NAD}^{+}$} & \multirow{2}{*}{$\begin{array}{c}\mathrm{NAD}^{+} / \mathrm{NADP}^{+} \\
{\left[k_{\text {cat }} / \mathrm{K}_{\mathrm{M}}\right]^{\mathrm{NAD}+} /\left[k_{\text {cat }} / \mathrm{K}_{\mathrm{M}}\right]^{\mathrm{NADP}+}}\end{array}$} & \multirow[b]{2}{*}{ Reference } \\
\hline & $\mathrm{K}_{M}(\mu \mathrm{M})$ & $k_{\text {cat }}\left(\mathbf{s}^{-1}\right)$ & $\mathrm{K}_{M}(\mu \mathrm{M})$ & $k_{\text {cat }}\left(\mathbf{s}^{-1}\right)$ & & \\
\hline Dicentrarchus labrax & 0.9 & & & & & 57 \\
\hline Ctenopharyngodon idella & 5.2 & & & & & 58 \\
\hline Catharanthus roseus (cytosolic) & 8.0 & & & & & 59 \\
\hline Catharantus roseus (plastidial) & 11.0 & & & & & 59 \\
\hline Candida utilis & 8 & 11 & & & & 60 \\
\hline Pisum sativum & 11.0 & & & & & 59 \\
\hline Pisum sativum (plastidial) & 23.0 & & & & & 59 \\
\hline Arthrobacter globiformis & 35.0 & & & & & \\
\hline Phormidium sp. & 13.0 & & & & & 61 \\
\hline Synechococcus 6307 & 25.0 & & & & & 62 \\
\hline Synechococcus 6716 & 10.0 & & & & & 62 \\
\hline Candida utilis type I & 20.0 & & & & & 63 \\
\hline Candida utilis type II & 20.0 & & & & & 63 \\
\hline Methylophilus methylotrophus & 25.0 & $5 \mathrm{U} / \mathrm{mg}^{*}$ & 9,050 & $\begin{array}{c}2.5 \\
\mathrm{U} / \mathrm{mg}^{\star}\end{array}$ & & 25 \\
\hline \multicolumn{7}{|l|}{ Tetrameric 6PGDH } \\
\hline Bradyrhizobium sp. & & & & $\begin{array}{l}31 \\
\mathrm{U} / \mathrm{mg}\end{array}$ & & 64 \\
\hline Gluconobacter oxydans & 440 & 41.5 & 64 & 41.7 & 6.9 & 28 \\
\hline Haloferax volcanii & 2900 & $0.42 \mathrm{U} / \mathrm{mg}^{*}$ & 33 & $\begin{array}{c}10 \\
\mathrm{U} / \mathrm{mg}\end{array}$ & & 3 \\
\hline Leuconostoc lactis & & & 320 & & & 65 \\
\hline Methylophilus methylotrophus & & & 105 & $\begin{array}{l}2.72 \\
\mathrm{U} / \mathrm{mg}\end{array}$ & & 25 \\
\hline Moorella thermoacetica & 13.9 & 8.7 & 1397 & & $1.4 \times 10-2$ & 27 \\
\hline Pseudomonas fluorescens & $23 \mathrm{U} / \mathrm{mg}^{\star}$ & & $121 \mathrm{U} / \mathrm{mg}$ * & & & 66 \\
\hline \multicolumn{7}{|l|}{$\begin{array}{l}\text { Uncharacterized oligomeric } \\
\text { state }\end{array}$} \\
\hline Pseudomonas multivorans I & 20 & & & & & 24 \\
\hline Pseudomonas multivorans II & 20 & & 200 & & & 24 \\
\hline
\end{tabular}

motif in the $\beta 2-\alpha 2$ loop $^{43}$. In the rest of sequences, the $\beta 2-\alpha 2$ loop showed moderate conservation of $\mathrm{D}$ and non-polar residues are slightly more frequent than $\mathrm{R}$ in the next position. Remarkably, the chloroflexi group did show the NR motif, suggesting preference for $\mathrm{NADP}^{+}$, although it was not possible to find reports of the enzymatic characterization for any representative in this clade.

Determinants of dinucleotide specificity in Go6PGDH Given that Go6PGDH can use both $\mathrm{NADP}^{+}$and $\mathrm{NAD}^{+}$ cofactors, we evaluated the effect of saturation of the $6 \mathrm{PG}$ binding site on the dinucleotide preference. We determined the kinetic parameters for the cofactors at a variety of $6 \mathrm{PG}$ concentrations, ranging from 0.25 to $7.2 \mathrm{mM}$ (in the case of $\mathrm{NADP}^{+}$) and 0.1 to $4 \mathrm{mM}$ (in the case of $\mathrm{NAD}^{+}$). A simple Michaelis-Menten model can be fitted to the data. Tertiary plots (Figure 8A and Figure 8B) showed that, for both dinucleotides the apparent $k_{\text {cat }}$ increases hyperbolically with the 6PG concentration, while the apparent $\mathrm{K}_{\mathrm{M}}$ decreases hyperbolically. At the asymptotes, we obtained the real kinetic parameters, for $\mathrm{NAD}^{+}$the $k_{\text {cat }}$ and $\mathrm{K}_{\mathrm{M}}$ was $47.4 \pm 1.2 \mathrm{~s}^{-1}$ and $20.1 \pm 3.2 \mu \mathrm{M}$, respectively. For $\mathrm{NADP}^{+}$instead, the $k_{\text {cat }}$ and $\mathrm{K}_{\mathrm{M}}$ was $41.4 \pm$ $2.8 \mathrm{~s}^{-1}$ and $285 \pm 25 \mu \mathrm{M}$, respectively (Figure $8 \mathrm{~A}$ and $8 \mathrm{~B}$, Table 4). The resulting real specificity constants at $6 \mathrm{PG}$ saturation 

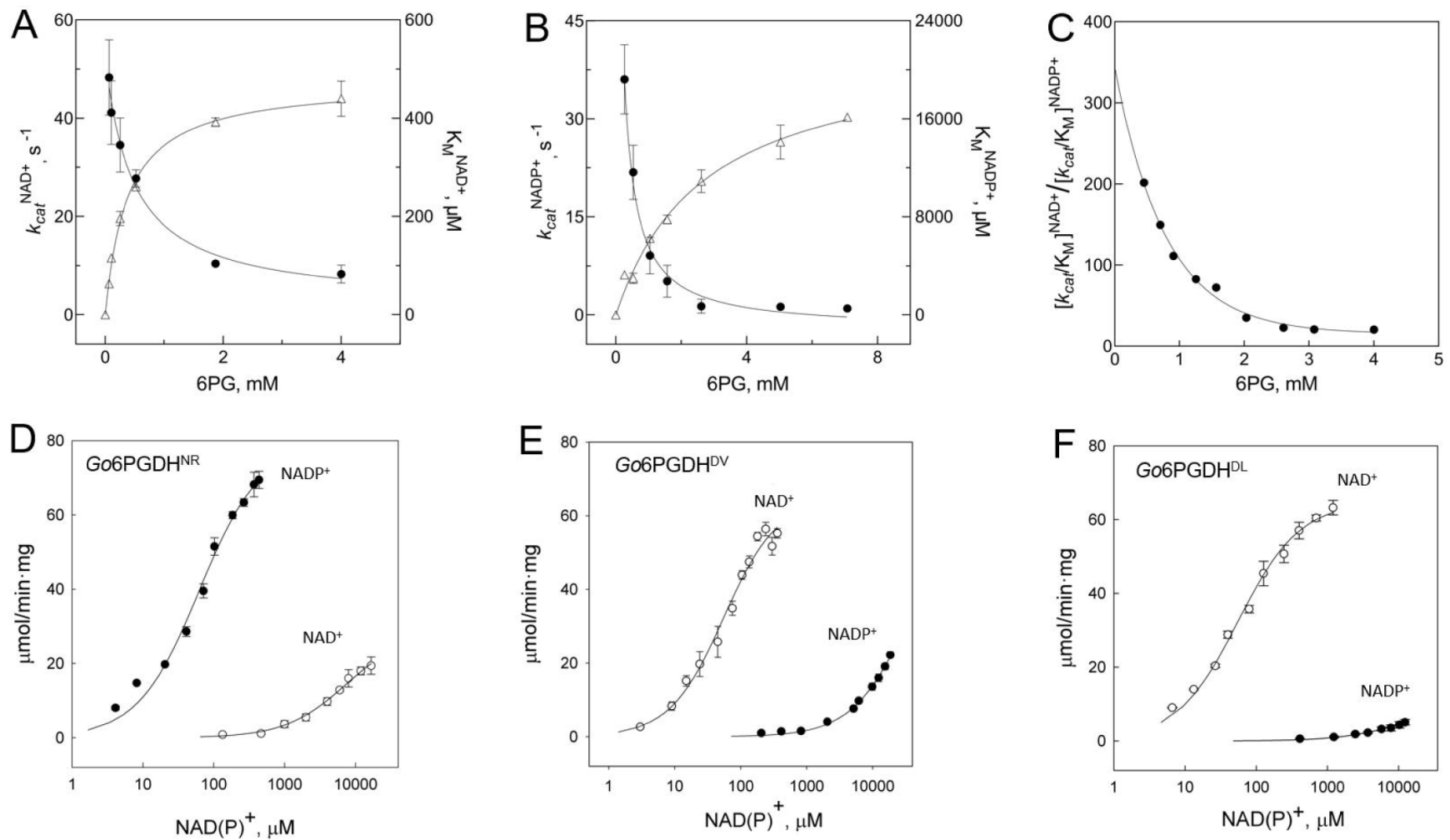

Figure 8. Effect of the 6PG concentration on the apparent kinetic parameters and consequence of mutations of conserved residues of the dinucleotide binding site of Go6PGDH. Kinetic parameter versus dinucleotide concentration (A, B). The best values for $k_{\text {cat }}$ (white triangles) and $\mathrm{K}_{\mathrm{M}}$ (black circles) were obtained from hyperbolic fitting of individual curves of $\mathrm{V}_{0}$ versus the NAD $(\mathbf{A})$ and $\mathrm{NADP}^{+}$ (B) concentration. Symbols indicate the average of three independent trials conducted at each 6PG concentration and the bars show the standard deviation.(C) Effect of 6PG concentration on the cofactor preference, as estimated from the quotient of specificity constants for $\mathrm{NAD}^{+}$over NADP+. A hyperbolic decay model was fitted to this behavior. From D to F, NADP+-dependent activity (black circles) and $\mathrm{NAD}^{+}$-dependent activity (white symbols) of $(\mathbf{A}) \mathrm{Go6PGDH}^{\mathrm{NR}},(\mathbf{B}) \mathrm{Go6PGDH}{ }^{\mathrm{DV}}$ and $(\mathbf{C}) \mathrm{Go6PGDH}{ }^{\mathrm{DL}}$ variants were measured at a saturating concentration of 6PG. In all cases $\mathrm{x}$-axis is shown as log-scale and the Michaelis-Menten equation was fitted to the data.

Table 4. Kinetic parameters of wild type Go6PGDH and mutants of the $\boldsymbol{\beta} 2$-a2 loop. Estimates were obtained using either NADP+ or $\mathrm{NAD}^{+}$as a substrate. The saturation curves of the mutant enzymes were carried out with $8 \mathrm{mM} 6 \mathrm{PG}$. Values correspond to the mean \pm standard deviation of three independent replicates.

\begin{tabular}{|c|c|c|c|c|c|c|c|}
\hline Protein & $\mathrm{K}_{\mathrm{M}}^{\mathrm{NAD+}}(\mu \mathrm{M})$ & $k_{\text {cat }}{ }^{\mathrm{NAD+}+}\left(\mathbf{s}^{-1}\right)$ & {$\left[k_{c a t} / \mathrm{K}_{\mathrm{M}}\right]^{\mathrm{NAD+}}\left(\mathbf{s}^{-1} / \mu \mathrm{M}\right)$} & $\mathrm{K}_{\mathrm{M}}^{\mathrm{NADP}+}(\mu \mathrm{M})$ & $k_{\text {cat }}{ }^{\mathrm{NADP}+}\left(\mathbf{s}^{-1}\right)$ & {$\left[k_{c a t} / \mathrm{K}_{\mathrm{M}}\right]^{\mathrm{NADP}+}\left(\mathrm{s}^{-1} / \mu \mathrm{M}\right)$} & {$\left[k_{c a t} / \mathrm{K}_{\mathrm{M}}\right]^{\mathrm{NAD}+} /\left[k_{c a t} / \mathrm{K}_{\mathrm{M}}\right]^{\mathrm{NADP}+}$} \\
\hline G06PGDH & $20.1 \pm 3.2$ & $47.4 \pm 1.2$ & 2.4 & $285 \pm 25$ & $41.4 \pm 2.8$ & 0.14 & 16 \\
\hline G06PGDHDV & $58 \pm 7$ & $42.5 \pm 3$ & 0.73 & $37160 \pm 6700$ & $42.2 \pm 4.1$ & $1.14 \times 10^{-3}$ & 640 \\
\hline G06PGDH $^{\mathrm{DL}}$ & $59 \pm 5$ & $44.5 \pm 2.6$ & 0.75 & $10134 \pm 3200$ & $4.7 \pm 0.8$ & $4.64 \times 10^{-4}$ & 1617 \\
\hline Go6PGDHNR & $7503 \pm 860$ & $18.5 \pm 1.5$ & $2.4 \times 10^{-3}$ & $62.2 \pm 7.1$ & $48 \pm 3$ & 0.77 & $3.31 \times 10^{-3}$ \\
\hline
\end{tabular}

(Table 4), are 0.14 and $2.4 \mathrm{~s}^{-1} \mu \mathrm{M}^{-1}$ for $\mathrm{NADP}^{+}$and $\mathrm{NAD}^{+}$, respectively. More importantly, the dependence of the specificity constant $k_{\text {cat }}^{\text {app } / K_{\mathrm{M}}}$ app with 6PG saturation differed for the two cofactors: at low $6 \mathrm{PG}$ concentrations the preference for $\mathrm{NAD}^{+}$ was more pronounced, reaching a value of 200 at $0.45 \mathrm{mM} 6 \mathrm{PG}$ and decreasing to 20.5 at $4 \mathrm{mM}$ (Figure 8C).
For the dinucleotide binding site, we focused on the DR motif of the $\beta 2-\alpha 2$ loop. These residues were replaced, in the case of $\mathrm{D} 30$ for $\mathrm{N}\left(G o 6 \mathrm{PGDH}^{\mathrm{NR}}\right)$, and in the case of $\mathrm{R} 31$ for $\mathrm{V}$ or $\mathrm{L}$ $\left(G o 6 \mathrm{PGDH}^{\mathrm{DV}}\right.$ and $G o 6 \mathrm{PGDH} \mathrm{DL}^{\mathrm{DL}}$, respectively). We determined the kinetic parameters for $\mathrm{NAD}^{+}$and $\mathrm{NADP}^{+}$at $8 \mathrm{mM} 6 \mathrm{PG}$, a saturating concentration for the wild-type enzyme. The 
mutant Go6PGDH ${ }^{\mathrm{NR}}$ showed a striking reversal of the cofactor preference (Figure 8D). The $\mathrm{K}_{\mathrm{M}}$ for $\mathrm{NAD}^{+}$increased more than 370 times over wild-type and the $k_{\text {cat }}$ decreased almost 3 times. For $\mathrm{NADP}^{+}$, the $\mathrm{K}_{\mathrm{M}}$ decreased almost 5 times and the $k_{\text {cat }}$ slightly increased with respect to wild type. The ratio of specificity constants changed from 16 favoring $\mathrm{NAD}^{+}$to 302 favoring $\mathrm{NADP}^{+}$(Table 4). On the other hand, R31 mutants showed a notable increase in the preference for $\mathrm{NAD}^{+}$compared to wild type: for the mutant $G o 6 \mathrm{PGDH}^{\mathrm{DV}}$ the $\mathrm{K}_{\mathrm{M}}$ for $\mathrm{NADP}^{+}$ increased 130 times (Figure $8 \mathrm{E}$ ) while the $k_{\text {cat }}$ remained unchanged (Table 4), and the $\mathrm{K}_{\mathrm{M}}$ for $\mathrm{NAD}^{+}$increased almost 3 times while the $k_{c a t}$ remained unchanged. Hence, the ratio of the specificity constant for $\mathrm{NAD}^{+}$over $\mathrm{NADP}^{+}$showed an enzyme 640-fold more specific for $\mathrm{NAD}^{+}$upon $\mathrm{R} 31 \mathrm{~V}$ mutation. Likewise, the mutant Go6 $\mathrm{PGDH}^{\mathrm{DL}}$ (Figure 8F) exhibits similar kinetic constants for $\mathrm{NAD}^{+}$as $G o 6 \mathrm{PGDH}^{\mathrm{DV}}$, but for $\mathrm{NADP}^{+}$the $\mathrm{K}_{\mathrm{M}}$ was more than $10 \mathrm{mM}$ and the $k_{\text {cat }}$ was $4,7 \mathrm{~s}^{-1}$ (Table 4), leading to a ratio of specificity constants for $\mathrm{NAD}^{+}$ over $\mathrm{NADP}^{+}$of 1617 upon R31L mutation (more than 100-fold more specific for $\mathrm{NAD}^{+}$than the wild type).

\section{Discussion}

\section{Architectural remodeling for the establishment of the} 6PG binding site

Our comparative analysis showed that major fold-level changes occurred concomitantly with the remodeling of the substrate binding site. The interchange of $\alpha$-helices between subunits preceded hemi-domain duplication and is the earliest hallmark in the evolution of the 6PGDH family. It is well known that recombination events can add or remove whole domains constituting long-scale mechanisms for domain architectural change ${ }^{67}$. In this context, tandem domain duplication provides a particular mechanism for modifying the oligomeric state of an enzyme without altering its function ${ }^{68-71}$. This occurred in the evolution of dimeric 6PGDHs, with the additional consideration that the duplication lead to the loss of two active sites in the oligomeric assembly. The described architectural remodeling could have been consequence of a destabilization of the interactions around the C-terminal $\alpha$-helix, together with an extension of the $\mathrm{C}$-terminal end. In fact, the number of residues after the C-terminal helix increases from $\beta \mathrm{HADHs}$ to tetrameric 6PGDHs and finally to dimeric 6PGDHs (not shown). Perhaps the kind of genetic instability that favored an increase in the number of residues also affected the tendency of recombination at that genetic locus.

In this context, it is expected that the tetrameric structure would be needed to provide the full set of interactions with 6PG. Surprisingly, Sarmiento-Pavía et $a .^{2}{ }^{2}$ observed a dimeric state of $G d 6 \mathrm{PGDH}$ in native gel electrophoresis, and proposed that the last C-terminal alpha helix could be a mean for association of this enzyme to the membrane. In this regard, first; we are not convinced that the sequence AEKVSMRFGF is mainly hydrophobic to interact with the membrane, and second; supporting the dimeric state only by native gel and omitting the tetrameric form of $G d 6 \mathrm{PGDH}$ built by crystallographic symmetry corresponds to a monumental error that does not contribute to understanding the structural evolution of the $6 \mathrm{PGDH}$ family. While Gd6PGDH might not form obligate tetramers and the rest of its residues at the binding pocket could still sustain 6PG binding, the cost would payed by a decreased catalytic efficiency. Perhaps that could be the reason why the observed $k_{\text {cat }}$ and $\mathrm{K}_{\mathrm{M}}$ values of $G d 6 \mathrm{PGDH}$ were lower and higher, respectively, than the corresponding values of Go6PGDH. We encourage the exploration of conditions for tetramer formation of $G d 6 \mathrm{PGDH}$, mostly as the equivalent tetramer observed here can be generated by crystallographic symmetry (Figure 3D), to determine its full activity and cofactor preference.

A clue about the substrate specificity of the ancestral form of $\beta$ HADHs could be drawn from the structural tree of the superfamily (Figure 5). One of the proteins that emerged closer to the root correspond to Hydroxymethyl-glutarate dehydrogenase (HMGDH; PDBid: 3CKY). It is noteworthy that the substrate of $\mathrm{HMGDH}$ is $6 \mathrm{C}$ long and bears multiple negatively charged groups, as does 6PG. It is plausible to think that the specificity towards 6PG could have originated from a similar substrate, whereas on the path leading to 3HIBADHs, a preference evolved favoring smaller substrates $\left(2-4 C^{72}\right)$. In fact, HMGDH showed some promiscuity towards $3 \mathrm{C}$ substrates, including 3 HIBAs. In this context, the sensitivity to 3HIBA inhibition displayed by Go6PGDH agrees with the idea that the tetrameric 6PGDHs are less differentiated than the dimeric forms in a pathway of increasing selectivity towards $6 \mathrm{PG}$.

\section{The presence of dimeric and tetrameric 6PGDHs across} species

Our phylogenetic results are consistent with 6PGDHs having appeared first in Bacteria and from them the different forms were transferred to Eukarya and Archaea (Figure 9). Lateral Gene Transfer (LGT) to Eukaryotes was apparent from at least three associations seen in the dimeric branch of 6PGDHs. The case of plants and cyanobacteria has been studied previously ${ }^{23}$. The close relationship of Opisthokonta with $\beta$ - and $\gamma$-proteobacteria (members of the clade $b_{l}$ ) has also been highlighted before ${ }^{23,73}$, but our analysis made clear that firmicutes was the most conspicuous bacterial group associated to these eukaryotes. Contrary to expectations based on their status as ancestors of mitochondria ${ }^{74}, \alpha$-proteobacterial sequences were not closely related to those of opisthokonta; ruling out that, like plants, the animal and fungal lineages would have acquired their nuclear genes for 6PGDH through endosymbiotic gene transfer. The most puzzling observation is that the clade $e_{3}$ (ascomycota+euglenozoa) is more ancient than plants and opisthokonta and yet it does not show a bacterial sister group (Figure 7). This might be due to either the loss of the 6PGDH gene in the bacterial lineage from which the gene was transferred, or an unsolved relationship with some of the close bacterial neighbours, perhaps $\alpha$-proteobacteria. On the other hand, although our reconstruction supports the hypothesis that haloarchaeal 6PGDHs were derived from bacterial homologs via $\mathrm{LGT}^{75}$, it also suggests that transference was not restricted to haloarchaea. It is noteworthy that the branching pattern of the bacterial lineages of dimeric and tetrameric 6PGDHs do not coincide, and particularly the main 


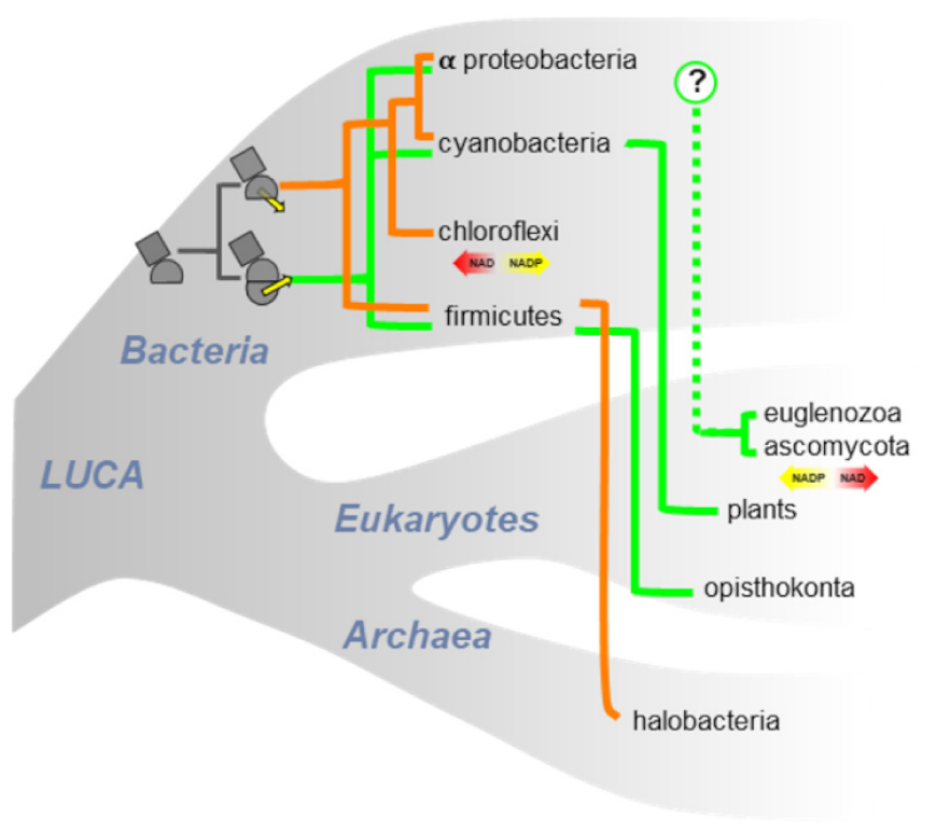

Figure 9. Overview of the evolutionary history of 6PGDHs. It is proposed that the family was originated in the Bacteria domain, where the homologous are more widespread, after the architectural changes occurred in the C-terminal hemi-domain. Only the clear monophyletic clades seen in Figure 7 are shown here. In the case of dimeric 6PGDHs, the branching order does not follow the phylogenetic tree of Figure 7, but the conventional view of bacterial phylogeny. Lateral Gene Transfer is indicated by vertical connectors between Domains. The dotted line raises the possibility that the 6PGDHs from the amorphea + excavata group could have evolved from $a$-proteobacteria. In the Chloroflexi and Ascomycota branches sequence conservation suggest a transition of cofactor specificity.

clades of dimeric 6PGDHs did not follow the conventional view of bacterial evolution ${ }^{76}$, probably because of extensive LGT and gene loss events.

The presence of multiple 6PGDH forms in single species was observed in different lineages (Figure 7 and Table 5). Plants possess plastidial and cytosolic variants of dimeric 6PGDH, both bearing an NR motif, which are derived from the duplication of an ancestral plastidial gene $\mathrm{g}^{23,73}$. In addition, we observed that Ascomycetes carry two dimeric 6PGDHs, one with the $\mathrm{NR}$ motif and the other with the $\mathrm{D} \phi$ motif (with $\phi=\mathrm{V}$ or $\mathrm{L}$ ), thus suggesting preference for $\mathrm{NADP}^{+}$and $\mathrm{NAD}^{+}$, respectively. Unlike plants, these fungi do not carry products of a recent gene duplication and their 6PGDH could even represent independent LGTs from different bacterial species. Interestingly, the presence of both tetrameric and dimeric 6PGDHs - possessing the D $\phi$ and the NR motifs, respectively - was found only among bacteria such as firmicutes (Lactobacillus plantarum, Leuconostoc mesenteroides, Lactococcus lactis, Enterococcus faecalis and Bacillus subtilis), actinobacteria (Streptomyces coelicolor) and $\beta$-proteobacteria (Methylobacillus flagellatus). Also, 6PGDHs that differ in size and cofactor specificity were reported for other bacteria in early biochemical studies ${ }^{26,66,77,78}$, that, unfortunately, had no access to the sequence features of the $\beta 2-\alpha 2$ loop. It is noteworthy that $\alpha$-proteobacteria and cyanobacteria possess either tetrameric or dimeric 6PGDHs, but individual species in these groups bearing both forms were not found.
Dinucleotide specificity in 6PGDHs, from engineering to evolution

The substrate saturation level of the 6PG binding site modulates the cofactor preference of Go6PGDH (Figure 8C). This feature could be physiologically relevant for dual dehydrogenases. Interestingly, the conservation of the DR motif in the clade of tetrameric 6PGDHs of $\alpha$-proteobacteria suggests dual cofactor specificity $^{43}$, and hence the possibility that the ratio of NADH to NADPH they produce could vary according to the intracellular $6 \mathrm{PG}$ concentration. On the other hand, the substrate-concentration dependence of $k_{\text {cat }}$ and $\mathrm{K}_{\mathrm{M}}$ for either cofactor indicates the formation of a ternary complex with 6PG and Go6PGDH, ruling out a ping-pong mechanism ${ }^{79}$. Similar kinetic results have been obtained for the dimeric 6PGDHs from Candida utilis ${ }^{80}$ and human erythrocytes ${ }^{81}$.

By changing the DR motif of Go6PGDH to D $\phi$; the specificity constant for $\mathrm{NADP}^{+}$dropped by at least 2 orders of magnitude (Table 4). This is explained by the absence of the guanidinium group of the $\mathrm{R}$ side chain that provides favorable interactions with the 2'-phosphate and the adenine ring of the cofactor, and also by the electrostatic repulsion with the negative charge of the aspartate carboxylate group. On the other hand, when changing the motif to NR, it was the specificity constant for $\mathrm{NAD}^{+}$which spectacularly dropped 1000-fold (Table 4). An explanation could be looked for in the crystal structures of dinucleotide-complexes of orthologues. In most of 6PGDH structures $\mathrm{N}_{\delta 2}$ from the $\mathrm{N}$ residue is an $\mathrm{H}$-bond donor to the 
Table 5. Orgnanism bearing 6PGDH isoforms present in the phylogenetic tree (see Figure 7.)

\begin{tabular}{|c|c|c|c|c|c|}
\hline Isoform & Uniprot & Kingdom & Class & $\begin{array}{l}\text { Sequence in } \\
\text { the } \beta 2-\alpha 2 \text { motif }\end{array}$ & $\begin{array}{l}\text { C-terminal } \\
\text { Hemi-domain }\end{array}$ \\
\hline Streptomyces coelicolor (1) & O88014 & Bacteria & Actinobacteria & YDTNPR & Single \\
\hline Streptomyces coelicolor (2) & Q7AKL1 & & & YDRNPDL & Single \\
\hline Streptomyces coelicolor (3) & Q93J68 & & & HNRTASR & Duplicated \\
\hline Heimdallarchaeota archaeon (1) & A0A2U3CDI6 & Archaea & Asgard group & KARSQKP & Single \\
\hline Heimdallarchaeota archaeon (2) & A0A2U3CCV3 & & & YNRTKSK & Duplicated \\
\hline Leuconostoc mesenteroides (1) & Q03YQ7 & Bacteria & Firmicutes & FDLNADF & Single \\
\hline Leuconostoc mesenteroides (2) & Q03XP2 & & & YNRSRER & Duplicated \\
\hline Lactococcus lactis (1) & A2RNY8 & Bacteria & Firmicutes & YDVNAEA & Single \\
\hline Lactococcus lactis (2) & P96789 & & & YNRTTSK & Duplicated \\
\hline Lactobacillus plantarum (1) & D7VB15 & Bacteria & Firmicutes & MDLNPTN & Single \\
\hline Lactobacillus plantarum (2) & D7V8V6 & & & FNRTGAK & Duplicated \\
\hline Bacillus subtilis (1) & P54448 & Bacteria & Firmicutes & YDVNQAA & Single \\
\hline Bacillus subtilis (2) & P80859 & & & YNRSSSK & Duplicated \\
\hline Bacillus subtilis (3) & P12013 & & & YNYTRDL & Duplicated \\
\hline Enterococcus faecalis (1) & EOHFQ9 & Bacteria & Firmicutes & FDVTKEA & Single \\
\hline Enterococcus faecalis (2) & EOH9P8 & & & YNRTGSK & Duplicated \\
\hline Methylobacillus flagellatus (1) & Q1H2F7 & Bacteria & Betaproteobacteria & FDFNQDA & Single \\
\hline Methylobacillus flagellatus (2) & Q1GY23 & & & YNRDPEK & Duplicated \\
\hline Coniosporium apollinis (1) & R7YPD3 & Fungi & Ascomycota & FNRTVSK & Duplicated \\
\hline Coniosporium apollinis (2) & R7YWE2 & & & WDISGEN & Duplicated \\
\hline Coniosporium apollinis (3) & $\mathrm{R} 7 \mathrm{YZH7}$ & & & QDPSVEA & Duplicated \\
\hline Macrophomina phaseolina (1) & K2S8M9 & Fungi & Ascomycota & YNRTVSK & Duplicated \\
\hline Coniosporium apollinis (2) & R7YWE2 & & & WDISGEN & Duplicated \\
\hline Trichophyton tonsurans (1) & F2S4G0 & Fungi & Ascomycota & FNRTVEK & Duplicated \\
\hline Trichophyton tonsurans (2) & F2S8U3 & & & WDAKADN & Duplicated \\
\hline Rasamsonia emersoni (1) & AOAOF4YZ37 & Fungi & Ascomycota & YNRTVSK & Duplicated \\
\hline Rasamsonia emersoni (2) & A0A0F4YQX6 & & & WDVSGPN & Duplicated \\
\hline Emericella nidulans (1) & Q5B676 & Fungi & Ascomycota & YNRTTSK & Duplicated \\
\hline Emericella nidulans (2) & C8VP36 & & & WDVKYDN & Duplicated \\
\hline Aspergillus oryzae (1) & Q8NKA5 & Fungi & Ascomycota & YNRTTSK & Duplicated \\
\hline Aspergillus oryzae (2) & Q8NKA4 & & & WDVKKEN & Duplicated \\
\hline Penicillium rubens (1) & B6GWT7 & Fungi & Ascomycota & YNRTTAK & Duplicated \\
\hline Penicillium rubens (2) & B6GYV9 & & & WDVVKKN & Duplicated \\
\hline Ricinus communis (1) chloroplastic & B9RVA7 & Plantae & Magnoliopsida & YNRSTSK & Duplicated \\
\hline Ricinus communis (2) chloroplastic & B9RCL8 & & & YNRSTSK & Duplicated \\
\hline Ricinus communis (3) & B9SXT4 & & & YNRTTSK & Duplicated \\
\hline Spinacia oleracea (1) chloroplastic & Q94KU2 & Plantae & Magnoliopsida & YNRTASK & Duplicated \\
\hline Spinacia oleracea (2) & Q94KU1 & & & YNRTTSK & Duplicated \\
\hline
\end{tabular}


backbone carbonyl of the residue $i+2$, which would otherwise be fully engaged in the H-bonding pattern of helix $\alpha 2$. In Go6PGDH, Gm6PGDH and Go6PGDH, an Asx turn ${ }^{82}$ is formed between the $\mathrm{O}_{\delta 1}$ of the $\mathrm{D}$ sidechain and the backbone amide of $i+2$, allowing the carbonyl to integrate the first turn of $\alpha 2$ (Figure 10). An Asx turn is also observed in the $\mathrm{NAD}^{+}$- complex of $H s 3 \mathrm{HIBADH}$, where the carboxylate of $\mathrm{D}$ performed as a bidentate $\mathrm{H}$-bond acceptor for the ribose hydroxyls. Therefore, we could hypothesize that upon the mutation from $\mathrm{D}$ to $\mathrm{N}$, the loss of the Asx turn induces a reordering of the $\mathrm{H}$-bond network and weakens the interactions with the ribose hydroxyls. This will be tested in planned structural work on dinucleotide-complexes of Go6PGDH and its mutants.

Altering the dinucleotide use of dehydrogenases has been an essential area of protein and metabolic engineering, as well as synthetic biology ${ }^{83-88}$. Thus far, studies on 6PGDHs seem to indicate that the tetrameric enzymes constitute a better scaffold to achieve high performance $\left(k_{c a t} / \mathrm{K}_{\mathrm{M}}\right)$ with $\mathrm{NAD}^{+}$by mutation of residues in the $\beta 2-\alpha 2$ loop, as well as high selectivity (ratio of $k_{\text {cat }} / \mathrm{K}_{\mathrm{M}}$ with $\mathrm{NAD}^{+}$to $k_{\text {cat }} / \mathrm{K}_{\mathrm{M}}$ with $\mathrm{NADP}^{+}$). Initial studies with the dimeric 6PGDH from Lactococcus lactis (which bears a NR motif), showed that the mutation R33Y worsened the enzyme's $\mathrm{K}_{\mathrm{M}}$ in presence of $\mathrm{NADP}^{+}$(increased above 700 -fold $)^{21}$. Although the mutant had measurable activity with $\mathrm{NAD}^{+}$, the activity level was insufficient for kinetic characterization. In the case of the hyperthermophilic dimeric

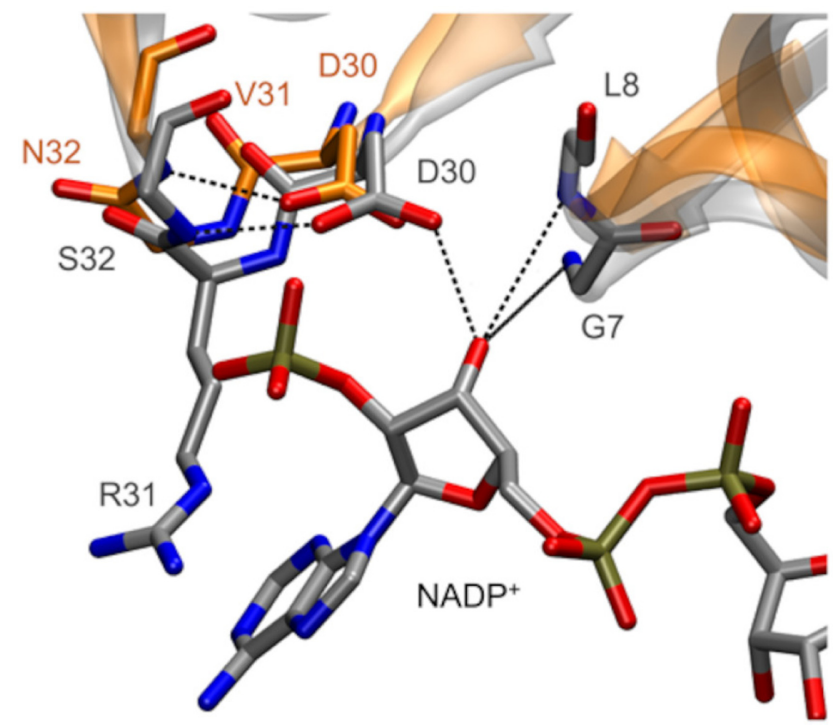

Figure 10. Superposition of the cofactor binding pocket of the Gm6PGDH and Go6PGDH. Gm6PGDH is represented in orange and Go6PGDH in gray, dotted lines represent $\mathrm{H}$-bonds. $\mathrm{O}_{\delta 1}$ of D30 interact with the amide of S32 and N32, in Gm6PGDH and Go6PGDH, respectively. The $\mathrm{O} 3$ of the $\mathrm{NADP}^{+}$ribose interacts as an acceptor of weak H-bonds with the amide group of G7 and L8 of Go6PGDH . Both Go6PGDH and Gm6PGDH display the structure of the Asx turn where the $\mathrm{O}_{\delta 2}$ of D30 interacts with the $\mathrm{O} 3$ of the ribose, which acts as an $\mathrm{H}$-bond donor.
$\mathrm{NADP}^{+}$-dependent $6 \mathrm{PGDH}$ from Thermotoga maritima, a triple site-directed mutant N32E/R33I/T34I was generated based on sequence alignment and docking of substrates/cofactors. Again, an important drop of the catalytic efficiency for $\mathrm{NADP}^{+}$as a cofactor was obtained, while the performance with $\mathrm{NAD}^{+}$only increased 3.6-fold. As a result, the selectivity for $\mathrm{NAD}^{+}$was 9620. Conversely, in the case of the thermophilic tetrameric $\mathrm{NADP}^{+}$-dependent 6PGDH from Moorella thermoacetica, the mutant A30D/R31I/T32I, was obtained through Directed Evolution $^{27}$. This time, the mutant showed an outstanding increase in the performance with $\mathrm{NAD}^{+}$. Given the 80 -fold decrease on the performance with $\mathrm{NADP}^{+}$, the resulting selectivity for $\mathrm{NAD}^{+}$was 61 . In this context, the kinetic parameters for Go6PGH $^{\mathrm{DL}}$ mutant (Table 4) showed a performance with $\mathrm{NAD}^{+}$higher than that of the Morella mutant and a selectivity far superior to that of the Thermotoga mutant.

The evolution of cofactor specificity of 6PGDHs directly impacts the metabolic role of the oxPPP. Our phylogenetic analysis revealed at least two instances of transition of cofactor specificity (Figure 7 and Figure 9): one in chloroflexi (tetrameric 6PGDHs) and the other in ascomycetes (clade $e_{3}$ of dimeric 6PGDHs). On the other hand, production of reduced cofactor in the oxPPP has been studied through physiological or enzymatic characterization. In the case of Bacillus subtilis it has been demonstrated the involvement of a dimeric $\mathrm{NADP}^{+}$dependent $6 \mathrm{PGDH}$ in the carbon flux through the oxPPP $^{89}$, even though this organism possesses variants that differ in size and cofactor specificity (Figure 7, Table 3 and Table 5). In the case of Haloferax volcanii a NADHproducing oxPPP has been described to operate, involving a $\mathrm{NAD}^{+}$-dependent tetrameric $6 \mathrm{PGDH}^{90}$. In the case of $G$. oxidans the oxPPP produce both reduced cofactors, since Go6PGDH generates mainly $\mathrm{NADH}$, whereas the glucose-6P dehydrogenase is engaged in NADPH production ${ }^{28}$. However, there remains an open question as to the metabolic constraints that determine the evolution of cofactor specificity of 6PGDHs.

\section{Data availability \\ Underlying data}

Protein Data Bank. X-ray data for the apo strtucture of the 6PGDH from Gluconobacter oxydans at Protein Data Bank, accession number: 6XEQ

https://www.rcsb.org/structure/6XEQ

Data for the analysis of the enzyme kinetics experiments. We did not save the raw data directly from the spectrophotometer (Absorbance units vs. time) for the kinetic experiments. However, we registered each slope $(\Delta \mathrm{A} / \mathrm{min})$ and deposited the data corresponding to specific enzyme activity (U/mg) vs. substrate concentration in the repository Zenodo (https:// zenodo.org/). With this information and proceeding with the described methodology, it is possible to set up all the graphs and kinetic parameters reported in this work.

Zenodo: Cofactor specificity of the tetrameric 6-phosphogluconate dehydrogenase from Gluconobacter oxydans: Studies of wild-type and mutants forms. https://doi.org/10.5281/zenodo.444833791 
This project contains the following underlying data:

-Cofactor preference vs 6PG.csv

-D30N-NAD.csv -D30N-NADP.csv

-Kinetic parameters NAD-6PG.csv

-Kinetic parameters NADP-6PG.csv

-NAD $(\mathrm{P})$ efficient constant vs 6PG .csv

\section{-R31L-NAD.csv}

-R31L-NADP.csv

-R31V-NAD.csv

\section{-R31V-NADP.csv}

Data are available under the terms of the Creative Commons Zero "No rights reserved" data waiver (CCO 1.0 Public domain dedication).

Zenodo: 6-phosphogluconate dehydrogenase activity inhibition by (S)-3-Hydroxyisobutyric acid. http://doi.org/10.5281/zenodo. $4537863^{48}$

This project contains the following underlying data:

-Inhibition_3HIBA.csv

Protein sequence codes used in the phylogenetic inference. Zenodo: Protein codes for tetrameric and dimeric 6-phosphogluconate dehydrogenases and their signature sequence relevant to the cofactor specificity in the 6PGDH family. https://doi. org/10.5281/zenodo. $4489052^{43}$
This project contains the following underlying data:

-Data_phylogenetic_tree.pdf

-Data_phylogenetic_tree.rtf

Data are available under the terms of the Creative Commons Attribution 4.0 International license (CC-BY 4.0).

\section{Acknowledgements}

We are grateful to Professor Marco Méndez from the Ecological Sciences Department, University of Chile for his advice in the phylogenetic analysis and Dr. Gabriel Vallejos for his complete revision of the manuscript. We gratefully acknowledge the help from Professor Uwe Deppenmeier from the Institute für Mikrobiologie und Biotechnologie, Bonn University, Germany, who kindly donated the DNA encoding Go6PGDH. This research used resources of the Brazilian Synchrotron Light Laboratory (LNLS), an open national facility operated by the Brazilian Center for Research in Energy and Materials (CNPEM) for the Brazilian Ministry for Science, Technology, Innovations, and Communications (MCTIC). The MX2 and SAXS2 beamlines staff are acknowledged for assistance during the experiments. PM thanks Dr. Andrey Z. Nascimento from the Brazilian National Synchrotron for assistance in data collection and processing. Also, PM thanks to the Latin American Center for Interdisciplinary Formation (CELFI) from the Argentinean Science Minister and the Center of Structural Biology of MERCOSUR (CEBEM) for the support received in courses and stays financing.
1. Csonka LN, Fraenkel DG: Pathways of NADPH formation in Escherichia coli. J Biol Chem. 1977; 252(10): 3382-3391. PubMed Abstract

2. Sarmiento-Pavía PD, Rodríguez-Hernández A, Rodríguez-Romero A, et al.: The structure of a novel membrane-associated 6-phosphogluconate dehydrogenase from Gluconacetobacter diazotrophicus (Gd6PGD) reveals a subfamily of short-chain 6PGDs. FEBS J. 2021; 288(4): 1286-1304. PubMed Abstract | Publisher Full Text

3. Pickl A, Schönheit P: The oxidative pentose phosphate pathway in the haloarchaeon Haloferax volcanii involves a novel type of glucose-6phosphate dehydrogenase--The archaeal Zwischenferment. FEBS Lett. 2015; 589(10): 1105-1111.

PubMed Abstract | Publisher Full Text

4. Park SC, Kim PH, Lee GS, et al.: Structural and biochemical characterization of the Bacillus cereus 3-hydroxyisobutyrate dehydrogenase. Biochem Biophys Res Commun. 2016; 474(3): 522-527.

PubMed Abstract | Publisher Full Text

5. Reitz S, Alhapel A, Essen LO, et al.: Structural and kinetic properties of a betahydroxyacid dehydrogenase involved in nicotinate fermentation.J Mol Biol. 2008; 382(3): 802-811.

PubMed Abstract | Publisher Full Text

6. Tchigvintsev A, Singer A, Brown G, et al.: Biochemical and structural studies of uncharacterized protein PA0743 from Pseudomonas aeruginosa revealed NAD+-dependent L-serine dehydrogenase. J Biol Chem. 2012; 287(3): 1874-1883. PubMed Abstract | Publisher Full Text | Free Full Text
7. Srikalaivani R, Singh A, Vijayan M, et al.: Structure, interactions and action of Mycobacterium tuberculosis 3-hydroxyisobutyric acid dehydrogenase. Biochem J. 2018; 475(15): 2457-2471.

PubMed Abstract | Publisher Full Text

8. Osipiuk J, Zhou M, Moy S, et al.: X-ray crystal structure of GarR-tartronate semialdehyde reductase from Salmonella typhimurium. J Struct Funct Genomics. 2009; 10(3): 249-253.

PubMed Abstract | Publisher Full Text | Free Full Text

9. Olivares P, Ulrich EC, Chekan JR, et al.: Characterization of Two Late-Stage Enzymes Involved in Fosfomycin Biosynthesis in Pseudomonads. ACS Chem Biol. 2017: 12(2): 456-463.

PubMed Abstract | Publisher Full Text | Free Full Text

10. Andreeva A, Murzin AG: Evolution of protein fold in the presence of functional constraints. Curr Opin Struct Biol. 2006; 16(3): 399-408. PubMed Abstract | Publisher Full Text

11. Phillips C, Gover S, Adams MJ: Structure of 6-phosphogluconate dehydrogenase refined at $2 \mathrm{~A}$ resolution. Acta Crystallogr D Biol Crystallogr. 1995; 51(Pt 3): 290-304. PubMed Abstract | Publisher Full Text

12. Lokanath NK, Ohshima N, Takio K, et al.: Crystal structure of novel NADP-dependent 3-hydroxyisobutyrate dehydrogenase from Thermus thermophilus HB8. J Mol Biol. 2005; 352(4): 905-917. PubMed Abstract | Publisher Full Text

13. Sippl MJ, Wiederstein M: Detection of spatial correlations in protein 
structures and molecular complexes. Structure. 2012; 20(4): 718-728. PubMed Abstract | Publisher Full Text | Free Full Text

14. Chen VB, Arendall WB 3rd, Headd JJ, et al.: MolProbity: all-atom structure validation for macromolecular crystallography. Acta Crystallogr D Biol Crystallogr. 2010; 66(Pt 1): 12-21.

PubMed Abstract | Publisher Full Text | Free Full Text

15. Hawes JW, Harper ET, Crabb DW, et al.: Structural and mechanistic similarities of 6-phosphogluconate and 3-hydroxyisobutyrate dehydrogenases reveal a new enzyme family, the 3-hydroxyacid dehydrogenases. FEBS Lett. 1996; 389(3): 263-267.

PubMed Abstract | Publisher Full Text

16. Cameron S, Martini VP, Iulek J, et al.: Geobacillus stearothermophilus 6-phosphogluconate dehydrogenase complexed with 6-phosphogluconate. Acta Crystallogr Sect F Struct Biol Cryst Commun. 2009; 65(Pt 5): 450-454. PubMed Abstract | Publisher Full Text | Free Full Text

17. Chen YY, Ko TP, Chen WH, et al.: Conformational changes associated with cofactor/substrate binding of 6-phosphogluconate dehydrogenase from Escherichia coli and Klebsiella pneumoniae: Implications for enzyme mechanism. J Struct Biol. 2010; 169(1): 25-35.

PubMed Abstract | Publisher Full Text

18. Haeussler K, Fritz-Wolf K, Reichmann M, et al.: Characterization of Plasmodium falciparum 6-Phosphogluconate Dehydrogenase as an Antimalarial Drug Target. J Mol Biol. 2018; 430(21): 4049-4067. PubMed Abstract | Publisher Full Text

19. Adams MJ, Ellis GH, Gover S, et al.: Crystallographic study of coenzyme, coenzyme analogue and substrate binding in 6-phosphogluconate dehydrogenase: implications for NADP specificity and the enzyme mechanism. Structure. 1994; 2(7): 651-668. PubMed Abstract | Publisher Full Text

20. Hitosugi T, Zhou L, Elf S, et al:: Phosphoglycerate mutase 1 coordinates glycolysis and biosynthesis to promote tumor growth. Cancer Cell. 2012; 22(5): 585-600.

PubMed Abstract | Publisher Full Text | Free Full Text

21. Tetaud E, Hanau S, Wells JM, et al.: 6-Phosphogluconate dehydrogenase from Lactococcus lactis: a role for arginine residues in binding substrate and coenzyme. Biochem J. 1999; 338(Pt 1): 55-60.

PubMed Abstract | Publisher Full Text | Free Full Text

22. Chen $\mathrm{H}$, Zhu Z, Huang R, et al.: Coenzyme Engineering of a Hyperthermophilic 6-Phosphogluconate Dehydrogenase from NADP+ to NAD+ with Its Application to Biobatteries. Sci Rep. 2016; 6: 36311 PubMed Abstract | Publisher Full Text | Free Full Text

23. Krepinsky $\mathrm{K}$, Plaumann $\mathrm{M}$, Martin $\mathrm{W}$, et al.: Purification and cloning of chloroplast 6-phosphogluconate dehydrogenase from spinach. Cyanobacterial genes for chloroplast and cytosolic isoenzymes encoded in eukaryotic chromosomes. EurJ Biochem. 2001; 268(9): 2678- 2686. PubMed Abstract | Publisher Full Text

24. Lee YN, Lessie TG: Purification and characterization of the two 6 phosphogluconate dehydrogenase species from Pseudomonas multivorans. J Bacteriol. 1974; 120(3): 1043-1057.

PubMed Abstract | Publisher Full Text | Free Full Text

25. Beardsmore AJ, Aperghis PNG, Quayle JR: Characterization of the assimilatory and dissimilatory pathways of carbon metabolism during growth of methylophilus methylotrophus on methanol. Microbiology. 1982 128(7): 1423-1439.

Publisher Full Text

26. Kiriuchin MY, Kletsova LV, Chistoserdov AY, et al.: Properties of glucose 6-phosphate and 6-phosphogluconate dehydrogenases of the obligate methylotroph Methylobacillus flagellatum KT. FEMS Microbiology Letters. 1988 52(3): 199-204.

Publisher Full Text

27. Huang $\mathrm{R}$, Chen $\mathrm{H}$, Zhong $\mathrm{C}$, et al.: High-Throughput Screening of Coenzyme Preference Change of Thermophilic 6-Phosphogluconate Dehydrogenase from NADP(+) to NAD(.). Sci Rep. 2016; 6: 32644.

PubMed Abstract | Publisher Full Text | Free Full Text

28. Rauch B, Pahlke J, Schweiger $\mathrm{P}$, et al.: Characterization of enzymes involved in the central metabolism of Gluconobacter oxydans. Appl Microbiol Biotechnol. 2010; 88(3): 711-718.

PubMed Abstract | Publisher Full Text

29. Olavarría K, Valdés D, Cabrera R: The cofactor preference of glucose-6phosphate dehydrogenase from Escherichia coli--modeling the physiological production of reduced cofactors. FEBS J. 2012; 279(13): 2296-2309. PubMed Abstract | Publisher Full Text

30. Guimarães BG, Sanfelici L, Neuenschwander RT, et al:: The MX2 macromolecular crystallography beamline: a wiggler $X$-ray source at the LNLS. J Synchrotron Radiat. 2009; 16(Pt 1): 69-75. PubMed Abstract | Publisher Full Text

31. Kabsch W: XDS. Acta Crystallogr D Biol Crystallogr. 2010; 66(Pt 2): 125-132. PubMed Abstract | Publisher Full Text | Free Full Text

32. Evans PR, Murshudov GN: How good are my data and what is the resolution? Acta Crystallogr D Biol Crystallogr. 2013; 69(Pt 7): 1204-1214. PubMed Abstract | Publisher Full Text | Free Full Text

33. Potterton L, Agirre J, Ballard C, et al.: CCP4i2: the new graphical user interface to the CCP4 program suite. Acta Crystallogr D Struct Biol. 2018; 74(Pt 2): 68-84. PubMed Abstract | Publisher Full Text | Free Full Text

34. Vagin A, Teplyakov A: Molecular replacement with MOLREP. Acta Crystallogr D Biol Crystallogr. 2010; 66(Pt 1): 22-25.

PubMed Abstract | Publisher Full Text

35. Emsley P, Cowtan K: Coot: model-building tools for molecular graphics. Acto Crystallogr D Biol Crystallogr. 2004; 60(Pt 12 Pt 1): 2126-2132. PubMed Abstract | Publisher Full Text

36. Afonine PV, Grosse-Kunstleve RW, Echols $\mathrm{N}$ et al: Towards automated crystallographic structure refinement with phenix.refine. Acta Crystallogr D Biol Crystallogr. 2012; 68(Pt 4): 352-367. PubMed Abstract | Publisher Full Text | Free Full Text

37. Franke D, Petoukhov MV, Konarev PV, et al: ATSAS 2.8: a comprehensive data analysis suite for small-angle scattering from macromolecular solutions. J Appl Crystallogr. 2017; 50(Pt 4): 1212-1225.

PubMed Abstract | Publisher Full Text | Free Full Text

38. Prlic $A$, Bliven $S$, Rose $P W$, et al:: Pre-calculated protein structure alignments at the RCSB PDB website Bioinformatics. 2010; 26(23): 2983-2985. PubMed Abstract | Publisher Full Text | Free Full Text

39. Roberts $E$, Eargle J, Wright $D$, et al.: MultiSeq: unifying sequence and structure data for evolutionary analysis. BMC Bioinformatics. 2006; 7: 382. PubMed Abstract | Publisher Full Text | Free Full Text

40. Johnson MS, Sali A, Blundell TL: Phylogenetic relationships from threedimensional protein structures. Methods Enzymol. 1990; 183: 670-690. PubMed Abstract | Publisher Full Text

41. Boc $A$, Diallo $A B$, Makarenkov V: T-REX: a web server for inferring, validating and visualizing phylogenetic trees and networks. Nucleic Acids Res. 2012 40(Web Server issue): W573-579.

PubMed Abstract | Publisher Full Text | Free Full Text

42. Krissinel $E$, Henrick $K$ : Inference of macromolecular assemblies from crystalline state. J Mol Biol. 2007; 372(3): 774-797. PubMed Abstract | Publisher Full Tex

43. Maturana P, Cabrera R: Protein codes for tetrameric and dimeric 6 phosphogluconate dehydrogenases and their signature sequence relevant to the cofactor specificity in the 6PGDH family. 2021. http://www.doi.org/10.5281/zenodo.4489052

44. Larkin MA, Blackshields G, Brown NP, et al: Clustal W and Clustal X version 2.0 Bioinformatics. 2007; 23(21): 2947-2948. PubMed Abstract | Publisher Full Text

45. Zhang C, Huelsenbeck JP, Ronquist F: Using Parsimony-Guided Tree Proposals to Accelerate Convergence in Bayesian Phylogenetic Inference. Syst Biol. 2020: 69(5): 1016-1032

PubMed Abstract | Publisher Full Text | Free Full Text

46. Whelan S, Goldman N: A general empirical model of protein evolution derived from multiple protein families using a maximum-likelihood approach. Mol Biol Evol. 2001; 18(5): 691-699. PubMed Abstract | Publisher Full Text

47. Njau RK, Herndon CA, Hawes JW: New developments in our understanding of the beta-hydroxyacid dehydrogenases. Chem Biol Interact. 2001; 130-132(1-3): 785-791.

PubMed Abstract | Publisher Full Text

48. Maturana P, Cabrera R: 6-phosphogluconate dehydrogenase activity inhibition by (S)-3-Hydroxyisobutyric acid. 2021 http://www.doi.org/10.5281/zenodo.4537863

49. Bridges RB, Palumbo MP, Wittenberger CL: Purification and properties of an NADP-specific 6-phosphogluconate dehydrogenase from Streptococcus faecalis. J Biol Chem. 1975; 250(15): 6093-6100.

PubMed Abstract | Publisher Full Text

50. Esteve MI, Cazzulo Jj: The 6-phosphogluconate dehydrogenase from Trypanosoma cruzi: the absence of two inter-subunit salt bridges as a reason for enzyme instability. Mol Biochem Parasitol. 2004; 133(2): 197-207. PubMed Abstract | Publisher Full Text

51. Dreifke M, Fried DI, Brieler FJ, et al.: Kinetic investigations of 6phosphogluconate dehydrogenase confined in mesoporous silica. $J \mathrm{Mol}$ Catal B Enzym. 2016; 132: 5-15. Publisher Full Text

52. Ito $S$, Osanai T: Single Amino Acid Change in 6-Phosphogluconate Dehydrogenase from Synechocystis Conveys Higher Affinity for NADP and Altered Mode of Inhibition by NADPH. Plant Cell Physiol. 2018; 59(12): 2452-2461.

PubMed Abstract | Publisher Full Text

53. He W, Wang Y, Liu W, et al.: Crystal structure of Saccharomyces cerevisiae 6-phosphogluconate dehydrogenase Gnd1. BMC Struct Biol. 2007; 7: 38 . PubMed Abstract | Publisher Full Text | Free Full Text

54. Simcox PD, Dennis DT: 6-phosphogluconate dehydrogenase isoenzymes from the developing endosperm of ricinus communis I. Plant Physiol. 1978; 62(2): 287-290.

PubMed Abstract | Publisher Full Text | Free Full Text

55. Sugimoto SI, Shiio I: Regulation of 6-Phosphogluconate Dehydrogenase in Brevibacterium flavum. Agric Biol Chem. 1987; 51(5): 1257-1263.

Publisher Full Text 
56. Corpas FJ, García-Salguero L, Barroso JB, et al.: Kinetic properties of hexosemonophosphate dehydrogenases. II. Isolation and partial purification of 6-phosphogluconate dehydrogenase from rat liver and kidney cortex. $\mathrm{Mol}$ Cell Biochem. 1995; 144(2): 97-104.

PubMed Abstract | Publisher Full Text

57. Medina-Puerta MM, Gallego-Iniesta M, Garrido-Pertierra A: Kinetic analysis of 6-phosphogluconate dehydrogenase from bass liver: effects of temperature and $\mathrm{pH}$ on its catalytic function. Arch Biochem Biophys. 1988, 262(1): 130-141.

PubMed Abstract | Publisher Full Text

58. Sun LD, Luo Z, Hu W, et al: Purification and characterization of 6-phosphogluconate dehydrogenase (6-PGD) from grass carp (Ctenopharyngodon idella) hepatopancreas. Indian J Biochem Biophys. 2013, 50(6): 554-561.

PubMed Abstract

59. Ishida $\mathrm{S}$, Ashihara $\mathrm{H}$ : Isoenzymes of phosphogluconate dehydrogenase (decarboxylating) from suspension-cultured Catharanthus roseus cells. Phytochemistry. The International Journal of Plant Biochemistry. 1993; 33(6): 1307-1311.

Publisher Full Text

60. Berdis AJ, Cook PF: Overall kinetic mechanism of 6-phosphogluconate dehydrogenase from Candida utilis. Biochemistry. 1993; 32(8): 2036-2040. PubMed Abstract | Publisher Full Text

61. Sawa $Y$ Suzuki $\mathrm{K}$, Ochiai $\mathrm{H}$ : Purification and Characterization of 6 Phosphogluconate Dehydrogenase from Phormidium sp. Agric Biol Chem. 1985; 49(9): 2543-2549. Publisher Full Text

62. Bot PVM, Lubberding $\mathrm{H}$ ): The influence of temperature on glucose-6phosphate dehydrogenase and 6-phosphogluconate dehydrogenase and the regulation of these enzymes in a mesophilic and a thermophilic cyanobacterium. Arch Microbiol. 1984; 137(9): 115-120. Publisher Full Text

63. Rippa M, Signorini M, Pontremoli S: Purification and properties of two forms of 6-phosphogluconate dehydrogenase from Candida utilis. Eur J Biochem. 1967; 1(2): 170-178.

PubMed Abstract | Publisher Full Text

64. Sosa-Saavedra F, León-Barrios M, Pérez-Galdona R: Pentose phosphate pathway as the main route for hexose catabolism in Bradyrhizobium sp. lacking Entner-Doudoroff pathway. A role for NAD+-dependent 6phosphogluconate dehydrogenase (decarboxylating). Soil Biol Biochem. 2001; 33(3): 339-343.

65. Ohara H, Russell RA, Uchida K, et al.: Purification and characterization of NAD-specific 6-phosphogluconate dehydrogenase from Leuconostoc lactis SHO-54. J Biosci Bioeng. 2004; 98(2): 126-128. PubMed Abstract | Publisher Full Text

66. Stournaras C, Maurer P, Kurz G: 6-phospho-D-gluconate dehydrogenase from Pseudomonas fluorescens. Properties and subunit structure. EurJ Biochem. 1983; 130(2): 391-396.

PubMed Abstract | Publisher Full Text

67. Buljan M, Frankish A, Bateman A: Quantifying the mechanisms of domain gain in animal proteins. Genome Biol. 2010; 11(7): R74. PubMed Abstract | Publisher Full Text | Free Full Text

68. Cahn JKB, Brinkmann-Chen S, Buller AR, et al.: Artificial domain duplication replicates evolutionary history of ketol-acid reductoisomerases. Protein $\mathrm{SC}$. 2016; 25(7): 1241-1248

PubMed Abstract | Publisher Full Text | Free Full Text

69. Abraham AL, Pothier J, Rocha EPC: Alternative to homo-oligomerisation: the creation of local symmetry in proteins by internal amplification. J Mol Biol. 2009; 394(3): 522-534.

PubMed Abstract | Publisher Full Text

70. Okvist M, Dey R, Sasso S, et al.: 1.6 A crystal structure of the secreted chorismate mutase from Mycobacterium tuberculosis: novel fold topology revealed. J Mol Biol. 2006; 357(5): 1483-1499. PubMed Abstract | Publisher Full Text

71. Yasutake $Y$, Watanabe $S$, Yao $M$, et al.: Crystal structure of the monomeric isocitrate dehydrogenase in the presence of NADP+: insight into the cofactor recognition, catalysis, and evolution. J Biol Chem. 2003; 278(38): 36897-36904.

PubMed Abstract | Publisher Full Text

72. Zhang $Y$, Zheng $Y$, Qin $L$, et al:: Structural characterization of a $\beta$ hydroxyacid dehydrogenase from Geobacter sulfurreducens and Geobacter metallireducens with succinic semialdehyde reductase activity. Biochimie. 2014; 104: 61-69.

PubMed Abstract | Publisher Full Text

73. Maruyama S, Misawa K, Iseki M, et al:: Origins of a cyanobacterial 6phosphogluconate dehydrogenase in plastid-lacking eukaryotes. BMC Evol Biol. 2008; 8: 151

PubMed Abstract | Publisher Full Text | Free Full Text

74. Gray MW: Mitochondrial evolution. Cold Spring Harb Perspect Biol. 2012; 4(9): a011403.

PubMed Abstract | Publisher Full Text | Free Full Text

75. Nelson-Sathi S, Dagan T, Landan G, et al.: Acquisition of 1,000 eubacterial genes physiologically transformed a methanogen at the origin of Haloarchaea. Proc Natl Acad Sci U S A. 2012; 109(50): 20537-20542. PubMed Abstract | Publisher Full Text | Free Full Text

76. Hug LA, Baker BJ, Anantharaman K, et al.: A new view of the tree of life. Nat Microbiol. 2016; 1: 16048

PubMed Abstract | Publisher Full Text

77. Demoss RD, Gibbs M: 6-Phosphogluconate dehydrogenase from leuconostoc mesenteroides J Bacteriol 1955: 70(6): 730-734. PubMed Abstract | Publisher Full Text | Free Full Text

78. Wyk JCV, Lessie TG: Purification and characterization of the Pseudomonas multivorans glucose-6-phosphate dehydrogenase active with nicotinamide adenine dinucleotide. J Bacteriol. 1974; 120(3): 1033-1042. PubMed Abstract | Publisher Full Text | Free Full Text

79. Cleland WW: The kinetics of enzyme-catalyzed reactions with two or more substrates or products. II. Inhibition: nomenclature and theory. Biochim Biophys Acta. 1963; 67: 173-187.

PubMed Abstract | Publisher Full Text

80. Berdis AJ, Cook PF: The 2'-phosphate of NADP is critical for optimum productive binding to 6-phosphogluconate dehydrogenase from Candida utilis. Arch Biochem Biophys. 1993; 305(2): 551-558.

PubMed Abstract | Publisher Full Text

81. Dallocchio F, Matteuzzi M, Bellini T: Half-site reactivity in 6 phosphogluconate dehydrogenase from human erythrocytes. Biochem $\mathrm{J}$ 1985; 227(1): 305-310.

PubMed Abstract | Publisher Full Text | Free Full Text

82. Thakur AK, Kishore R: Characterization of beta-turn and Asx-turns mimicry in a model peptide: stabilization via C--H ... O interaction. Biopolymers. 2006; 81(6): 440-449.

PubMed Abstract | Publisher Full Text

83. Akhtar MK, Jones PR: Cofactor engineering for enhancing the flux of metabolic pathways. Front Bioeng Biotechnol. 2014; 2: 30 . PubMed Abstract | Publisher Full Text | Free Full Text

84. Wang $M$, Chen $B$, Fang $Y$, et al.: Cofactor engineering for more efficient production of chemicals and biofuels. Biotechnol Adv. 2017; 35(8): 1032-1039. PubMed Abstract | Publisher Full Text

85. Varman AM, Yu Y, You L, et al.: Photoautotrophic production of D-lactic acid in an engineered cyanobacterium. Microb Cell Fact. 2013; 12: 117. PubMed Abstract | Publisher Full Text | Free Full Text

86. You C, Huang R, Wei $X$, et al.: Protein engineering of oxidoreductases utilizing nicotinamide-based coenzymes, with applications in synthetic biology. Synth Syst Biotechnol. 2017; 2(3): 208-218. PubMed Abstract | Publisher Full Text | Free Full Text

87. Zhu Z, Tam TK, Sun F, et al.: A high-energy-density sugar biobattery based on a synthetic enzymatic pathway. Nat Commun. 2014; 5: 3026. PubMed Abstract | Publisher Full Text

88. Li C, Tao F, Ni J, et al.: Enhancing the light-driven production of D-lactate by engineering cyanobacterium using a combinational strategy. Sci Rep. 2015; 5: 9777.

PubMed Abstract | Publisher Full Text | Free Full Text

89. Zamboni $\mathrm{N}$, Fischer $\mathrm{E}$, Laudert $\mathrm{D}$, et al.: The Bacillus subtilis yqjI gene encodes the NADP+-dependent 6-P-gluconate dehydrogenase in the pentose phosphate pathway. J Bacteriol. 2004; 186(14): 4528-4534. PubMed Abstract | Publisher Full Text | Free Full Text

90. Soderberg T: Biosynthesis of ribose-5-phosphate and erythrose-4phosphate in archaea: a phylogenetic analysis of archaeal genomes. Archaea. 2005; 1(5): 347-352.

PubMed Abstract | Publisher Full Text | Free Full Text

91. Maturana P, Tobar E, Cabrera R: Cofactor specificity of the tetrameric 6phosphogluconate dehydrogenase from Gluconobacter oxydans: Studies of wild-type and mutants forms. 2021

http://www.doi.org/10.5281/zenodo.4448337 


\section{Open Peer Review}

\section{Current Peer Review Status:}

Version 1

Reviewer Report 01 June 2021

https://doi.org/10.21956/wellcomeopenres.18264.r43777

(C) 2021 Engel P. This is an open access peer review report distributed under the terms of the Creative Commons Attribution License, which permits unrestricted use, distribution, and reproduction in any medium, provided the original work is properly cited.

\section{Paul C. Engel \\ School of Biomolecular and Biomedical Science, Conway Institute, University College Dublin, Dublin, Ireland}

This is an ambitious and interesting study which attempts to draw together much information on primary, tertiary and quaternary structure in 6-phosphogluconate dehydrogenases from a wide variety of biological species, and also on related enzymes, in order to arrive at a proposed model for the sequence of evolutionary development in this enzyme family. The paper is generally clear and well written. Only time will tell how close the authors are to the truth in their interpretation, but they offer a plausible account, and papers like this do a service to everyone in having the courage to look beyond the immediate local details to survey the wider landscape. They put some of their conclusions (with regard to the basis of coenzyme specificity) to direct experimental test through mutagenesis, achieving dramatic shifts in the predicted direction in coenzyme preference.

I have only a few scientific points and a few minor language corrections.

\section{Scientific points:}

1. Discussion of Fig. 6: The authors explore their idea about the evolutionary relationship between 3-hydroxyacid dehydrogenases and 6PGDHs by looking at the response of two different 6PGDHs to 3HIBA. Neither shows any catalytic activity, but one displays significant inhibition. The interpretation here needs caution and some qualification, because the pattern, with a plateau at roughly $30 \%$ inhibition, is not what one would expect for a competitive inhibition. The experiment ideally could have done with a control using a similar compound not predicted to have any vestigial affinity for the substrate site in order to rule out (or in) a non-specific binding effect.

2. Discussion section, paragraph 2: The phrase 'monumental error' in discussing the relative merits of evidence from crystallography and from native gels is over the top. What is needed here is a fuller discussion of the relevant parameters (protein concentration, solvent components, concentration $\mathrm{pH}$ etc.) that might influence the predominant quaternary structure. Crystallography also offers a snapshot of behaviour under a particular set of 
conditions and not necessarily absolute, unconditional and exclusive truth.

3. The final Discussion would benefit from some mention of the extent to which the means by which different coenzyme preferences are achieved in this family are or are not similar to those seen in other dehydrogenase families. This is, after all, in the wider context, a story that has been under study for different dehydrogenases for over thirty years.

Language details, etc.:

1. In Expression and Protein Purification: "...biomass was collected...".

2. Table 1 title: Crystallography.

3. Structural Alignment and analysis: "...are listed in Table 2."

4. Fig. 3 Legend last word: "shown."

5. Discussion paragraph 2: "...could be a means...".

6. Table 5 title: "Organisms bearing...".

7. Last paragraph before Data Availability: "In the case of Bacillus subtilis the involvement ... has been demonstrated...".

Is the work clearly and accurately presented and does it cite the current literature? Yes

Is the study design appropriate and is the work technically sound?

Yes

Are sufficient details of methods and analysis provided to allow replication by others? Yes

If applicable, is the statistical analysis and its interpretation appropriate? Yes

Are all the source data underlying the results available to ensure full reproducibility? Yes

Are the conclusions drawn adequately supported by the results?

Yes

Competing Interests: No competing interests were disclosed.

Reviewer Expertise: Enzymology, kinetics, protein engineering

I confirm that I have read this submission and believe that I have an appropriate level of expertise to confirm that it is of an acceptable scientific standard, however I have 
significant reservations, as outlined above.

Reviewer Report 12 May 2021

https://doi.org/10.21956/wellcomeopenres.18264.r43536

(C) 2021 C. Gómez J. This is an open access peer review report distributed under the terms of the Creative Commons Attribution License, which permits unrestricted use, distribution, and reproduction in any medium, provided the original work is properly cited.

\section{José Gregório C. Gómez}

Department of Microbiology, Institute of Biomedical Sciences, University of São Paulo, São Paulo, Brazil

This article describes an interesting scientific work very well carried out and presenting results that are relevant to the general knowledge of cellular metabolism. The crystallographic structure of 6-phosphogluconate dehydrogenase from Gluconobacter oxidans (Go6PGDH) was resolved and described. Taking into account phylogenetic trees based on structure or aminoacids sequence and the inhibitory effects of 3-hydro-isobutyrate, evolutive aspects and lateral genetic transfers were proposed. Mutants of Go6PGDH were constructed and important features were revealed regards NAD or NADP specificities.

I consider this article to be of excellent quality and indicate only minor points that could improve it.

At the beginning of the introduction, the authors could already make it clear that the reaction catalyzed by 6PGDHs is part of the oxidative part of the pentose phosphate pathway (oxPPP). This abbreviation appears only in the last paragraph of the discussion without being clarified in any previous part of the article.

Enzyme activity data using NAD or NADP for 6PGDH from Pseudomonas putida KT2440 are also available from Olavarria et al. $\left(2015^{1}\right)$. These data could be used to enrich Table 3.

The fact that some bacteria do not have the gnd gene (encoding 6PGDH) could have been better discussed. Effects of gnd expression with different specificities (NAD or NADP) in a Pseudomonas sp. without the gnd gene in its genome have been addressed recently (Cardinali-Rezende et al., 2020²).

\section{References}

1. Olavarria K, Marone MP, da Costa Oliveira H, Roncallo JC, et al.: Quantifying NAD(P)H production in the upper Entner-Doudoroff pathway from Pseudomonas putida KT2440.FEBS Open Bio. 2015; 5: 908-15 PubMed Abstract | Publisher Full Text

2. Cardinali-Rezende J, Di Genova A, Nahat RATPS, Steinbüchel A, et al.: The relevance of enzyme specificity for coenzymes and the presence of 6-phosphogluconate dehydrogenase for polyhydroxyalkanoates production in the metabolism of Pseudomonas sp. LFM046.Int J Biol Macromol. 2020; 163: 240-250 PubMed Abstract | Publisher Full Text 
Is the work clearly and accurately presented and does it cite the current literature? Yes

Is the study design appropriate and is the work technically sound?

Yes

Are sufficient details of methods and analysis provided to allow replication by others? Yes

If applicable, is the statistical analysis and its interpretation appropriate? Yes

Are all the source data underlying the results available to ensure full reproducibility? Yes

Are the conclusions drawn adequately supported by the results?

Yes

Competing Interests: No competing interests were disclosed.

Reviewer Expertise: bacterial metabolism; bacterial biotechnology; polyhydroxyalkanoates

I confirm that I have read this submission and believe that I have an appropriate level of expertise to confirm that it is of an acceptable scientific standard. 